\title{
Synthesis and Optimization of Visible Light Active BiVO Photocatalysts for the Degradation of RhB
}

\author{
Rong Ran, ${ }^{1,2}$ Joanne Gamage McEvoy, ${ }^{1,2}$ and Zisheng Zhang ${ }^{1,2}$ \\ ${ }^{1}$ Department of Chemical and Biological Engineering, University of Ottawa, Ottawa, ON, Canada K1N 6N5 \\ ${ }^{2}$ Centre for Catalysis Research and Innovation, University of Ottawa, Ottawa, ON, Canada K1N 6N5 \\ Correspondence should be addressed to Zisheng Zhang; zzhang@uottawa.ca
}

Received 9 May 2015; Accepted 15 July 2015

Academic Editor: Mohammad Muneer

Copyright (c) 2015 Rong Ran et al. This is an open access article distributed under the Creative Commons Attribution License, which permits unrestricted use, distribution, and reproduction in any medium, provided the original work is properly cited.

\begin{abstract}
Monoclinic $\mathrm{BiVO}_{4}$ powders were synthesized via a novel route using potassium metavanadate $\left(\mathrm{KVO}_{3}\right)$ prepared by calcination of $\mathrm{K}_{2} \mathrm{CO}_{3}$ and $\mathrm{V}_{2} \mathrm{O}_{5}$ as a starting material and followed by hydrothermal treatment and were investigated for the degradation of Rhodamine $\mathrm{B}(\mathrm{RhB})$ under visible light irradiation. The synthesized $\mathrm{BiVO}_{4}$ particles were characterized by X-ray diffraction (XRD), scanning electron microscopy (SEM), X-ray photoelectron spectroscopy (XPS), and UV-Visible (UV-Vis) light diffuse reflectance spectrophotometry. The synthesis produced pure monoclinic $\mathrm{BiVO}_{4}$ particles with multimorphological features containing flowerlike, flake-ball, flake, cuboid-like, and plate-like shapes and exhibited strong absorption in the visible light range. $\mathrm{The}^{\mathrm{BiVO}} \mathrm{O}_{4}$ prepared via $\mathrm{KVO}_{3}$ possessed excellent photocatalytic activity for the degradation of $\mathrm{RhB}$ under visible light. The performance of this catalyst was found to be superior to other $\mathrm{BiVO}_{4}$ photocatalysts prepared via ammonium metavanadate $\left(\mathrm{NH}_{4} \mathrm{VO}_{3}\right)$ using coprecipitation, combustion, and calcination methods reported in literature, respectively.
\end{abstract}

\section{Introduction}

$\mathrm{BiVO}_{4}$ is a promising semiconductor for use in solar photocatalysis due to its efficient visible light absorption and other favorable properties such as its nontoxicity $[1,2] . \mathrm{BiVO}_{4}$ exists in three major crystal phases, namely, monoclinic scheelite, tetragonal zircon, and tetragonal scheelite $[3,4]$. Of these, monoclinic $\mathrm{BiVO}_{4}$ possesses a band gap of $2.4 \mathrm{eV}$, making it the most appropriate $\mathrm{BiVO}_{4}$ phase for applications to visiblelight-induced photocatalysis $[5,6]$. Solid state reactions are traditionally used for the synthesis of $\mathrm{BiVO}_{4}[7,8]$; however other synthesis methods such as sonochemical routes $[9,10]$, room temperature aqueous processes [3], molten salt methods [11], hydrothermal processes [12,13], chemical bath depositions [14, 15], organic decompositions [16, 17], combustion synthesis [18], and coprecipitation processes [19] have been recently proposed and investigated.

In order to enhance the photodegradation efficiency of the composite, various $\mathrm{BiVO}_{4}$ morphologies such as flowerlike [5], flake-ball, flake [20], cuboid-like, and plate-like [21] structures exhibiting enhanced surface area for photocatalysis have been reported. However, most of the synthesis methods investigated cannot result in the synthesis of $\mathrm{BiVO}_{4}$ materials with both high crystallinity and high surface areas required for efficient photocatalytic reactions $[9,18]$. In order to address these issues and to optimize the photocatalytic properties of monoclinic $\mathrm{BiVO}_{4}$, certain research efforts have been focused on employing templates and surfactants such as silica (KIT-6) [22] and CTAB [21] and CMC [19] and starting materials made from organic polymers and inorganic salts [23]. However, the generated impurities from these methods may be responsible for the blockage of active sites on $\mathrm{BiVO}_{4}$ particles, decreasing the overall photocatalytic activity.

In recent years, potassium vanadium oxides, particularly $\mathrm{KVO}_{3}$ and $\mathrm{K}_{3} \mathrm{VO}_{8}$, have been reported as promising alternative starting materials for the preparation of monoclinic $\mathrm{BiVO}_{4}[24,25]$. For example, Kelmers [26] prepared $\mathrm{KVO}_{3}$ precursor by dissolving equimolar amounts of $\mathrm{K}$ and $\mathrm{V}$, as $\mathrm{KOH}$ and $\mathrm{V}_{2} \mathrm{O}_{5}$, respectively. $\mathrm{KVO}_{3}$ was also previously prepared using $\mathrm{KCl}$ and $\mathrm{V}_{2} \mathrm{O}_{5}$ in the presence of steam [27]. Liu et al. [28] reported using $\mathrm{NaVO}_{3}$ and $\mathrm{V}_{2} \mathrm{O}_{5}$ as two different vanadium sources to synthesize $\mathrm{BiVO}_{4}$ particles via a hydrothermal method (at synthesis conditions of $140^{\circ} \mathrm{C}$ from 
TABLE 1: Synthesis parameters of $\mathrm{BiVO}_{4}$ samples prepared via hydrothermal method.

\begin{tabular}{|c|c|c|c|}
\hline Sample (sample name) & Reactants & $\begin{array}{l}\mathrm{pH} \text { of precursor } \\
\text { slurry }\end{array}$ & Temperature \& time \\
\hline \multirow{4}{*}{$\mathrm{BiVO}_{4}(\mathrm{H}-140-8)$} & $3 \mathrm{mmol} \mathrm{Bi}\left(\mathrm{NO}_{3}\right)_{3} \cdot 5 \mathrm{H}_{2} \mathrm{O}$ & \multirow{4}{*}{$7\left(2 \mathrm{M} \mathrm{NH}_{4} \mathrm{OH}\right)$} & \multirow{4}{*}{$\begin{array}{l}\text { Hydrothermal } 140^{\circ} \mathrm{C} \text {, } \\
8 \mathrm{~h}[29] .\end{array}$} \\
\hline & $2 \mathrm{mmol} \mathrm{NH}_{4} \mathrm{VO}_{3}$ & & \\
\hline & $2 \mathrm{M} \mathrm{NH}_{4} \mathrm{OH}$ & & \\
\hline & $35 \mathrm{~mL}$ deionized water (DW) & & \\
\hline \multirow{5}{*}{$\mathrm{BiVO}_{4}(\mathrm{C}+\mathrm{H}-200-24)$} & $3 \mathrm{mmol} \mathrm{Bi}\left(\mathrm{NO}_{3}\right)_{3} \cdot 5 \mathrm{H}_{2} \mathrm{O}$ & \multirow{5}{*}{$\begin{array}{l}1(50 \text { vol. } \% \text { acetic } \\
\text { acid })\end{array}$} & \multirow{5}{*}{$\begin{array}{l}\text { Precursor calcination } \\
730 \mathrm{~K}\left(457^{\circ} \mathrm{C}\right), 5 \mathrm{~h} ; \\
\text { hydrothermal } 200^{\circ} \mathrm{C} \text {, } \\
24 \mathrm{~h}[24] .\end{array}$} \\
\hline & $0.38 \mathrm{~g} \mathrm{~K}_{2} \mathrm{CO}_{3}$ & & \\
\hline & $0.5 \mathrm{~g} \mathrm{~V}_{2} \mathrm{O}_{5}$ & & \\
\hline & 50 vol. $\%$ acetic acid & & \\
\hline & $35 \mathrm{~mL} \mathrm{DW}$ & & \\
\hline
\end{tabular}

Samples prepared via hydrothermal synthesis were denoted by the nomenclature $\mathrm{BiVO}_{4}(\mathrm{H}-\mathrm{XXX}-\mathrm{XX})$, where $\mathrm{XXX}$ and XX refer to the treatment temperature and time, respectively; $\mathrm{BiVO}_{4}(\mathrm{H}-\mathrm{XXX}-\mathrm{XX})$ and $\mathrm{BiVO}_{4}(\mathrm{C}+\mathrm{H}-\mathrm{XXX}-\mathrm{XX})$ denote samples prepared via hydrothermal and calcination and hydrothermal synthesis, respectively.

$\mathrm{NaVO}_{3}$ and $200^{\circ} \mathrm{C}$ from $\mathrm{V}_{2} \mathrm{O}_{5}$ ), to obtain two different morphologies of $\mathrm{BiVO}_{4}$ particles with a plate form and rodlike shapes, respectively.

In this work, a novel method for the preparation of monoclinic $\mathrm{BiVO}_{4}$ via $\mathrm{KVO}_{3}$ starting material prepared by facile calcination of $\mathrm{K}_{2} \mathrm{CO}_{3}$ and $\mathrm{V}_{2} \mathrm{O}_{5}$ was investigated. $\mathrm{BiVO}_{4}$ synthesized via this route and subsequent hydrothermal synthesis was compared to a similar hydrothermally prepared $\mathrm{BiVO}_{4}$ obtained via $\mathrm{NH}_{4} \mathrm{VO}_{3}$ starting material. In addition, $\mathrm{BiVO}_{4}$ synthesized was compared to $\mathrm{BiVO}_{4}$ synthesized by other methods reported in literature, such as coprecipitation, combustion, and calcination. Compared to $\mathrm{BiVO}_{4}$ obtained by all other synthesis methods, the as-prepared $\mathrm{BiVO}_{4}$ synthesized via the novel route proposed exhibited enhanced photocatalytic activity for the degradation of model organic pollutant, Rhodamine B (RhB), under visible light irradiation due to its desirable phase structure, morphologies, and surface areas. There have been no reports to date on the synthesis of monoclinic $\mathrm{BiVO}_{4}$ powders via $\mathrm{KVO}_{3}$ and the hydrothermal method; therefore the study of this material and its enhanced performance when prepared via this route contributes to the advancement of visible light photocatalysis using novel bismuth-based structures.

\section{Experimental}

2.1. Catalyst Synthesis. All chemicals used were of analytical purity. $\mathrm{BiVO}_{4}$ was synthesized in a two-step procedure, where potassium metavanadate $\left(\mathrm{KVO}_{3}\right)$ was first prepared by calcination, followed by the hydrothermal synthesis of monoclinic $\mathrm{BiVO}_{4}$ particles. In the first process, $0.38 \mathrm{~g} \mathrm{~K}_{2} \mathrm{CO}_{3}$ (Fisher Scientific, Certified ACS) and $0.5 \mathrm{~g} \mathrm{~V}_{2} \mathrm{O}_{5}$ (ACROS Organics, 99.6\%) were dissolved in $35 \mathrm{~mL}$ deionized water (DW) under vigorous magnetic stirring. The resulting red solution was then poured into an evaporation dish and dried at $50^{\circ} \mathrm{C}$ in an oven overnight. The dry sample was then ground and annealed in air at $457^{\circ} \mathrm{C}(730 \mathrm{~K})$ for $5 \mathrm{~h}$, resulting in a pink $\mathrm{KVO}_{3}$ powder. To prepare $\mathrm{BiVO}_{4}, 1 \mathrm{mmol} \mathrm{Bi}\left(\mathrm{NO}_{3}\right)_{3} \cdot 5 \mathrm{H}_{2} \mathrm{O}$ and $0.1056 \mathrm{~g}$ of the prepared $\mathrm{KVO}_{3}$ powder were mixed in
$35 \mathrm{~mL}$ DW and allowed to react under continuous stirring for 50 min to obtain a vivid yellow slurry. The $\mathrm{pH}$ of the slurry was then adjusted by adding 50 vol. $\%$ acetic acid, until a final $\mathrm{pH}$ of $\sim 1$ was reached. The slurry was then transferred into a $45 \mathrm{~mL}$ Teflon-lined stainless steel autoclave and the reaction was allowed to proceed at $200^{\circ} \mathrm{C}$ for $24 \mathrm{~h}$. The resulting solid was collected by filtration, washed with DW several times, and then dried in air overnight.

To investigate the influence of starting materials on the photocatalytic activity of $\mathrm{BiVO}_{4}$ prepared via the hydrothermal method, two hydrothermal synthesis routes were investigated, namely, via $\mathrm{KVO}_{3}$ and via $\mathrm{NH}_{4} \mathrm{VO}_{3}$, respectively, as outlined in Table 1. In order to compare the morphologies, optical properties, and photocatalytic activities of $\mathrm{BiVO}_{4}$ obtained by the proposed hydrothermal synthesis to properties of $\mathrm{BiVO}_{4}$ prepared via various other syntheses reported in the literature, a number of alternative synthesis methods were also explored, as outlined in Table 2. The nomenclature for the as-prepared $\mathrm{BiVO}_{4}$ samples is given in Table 1 for two samples prepared via hydrothermal synthesis and Table 2 for samples prepared via other synthesis methods. It should be noted that the operating parameters selected for the various syntheses methods shown in Table 1 were adopted from the optimal parameters reported in the corresponding literatures.

2.2. Characterization. X-ray powder diffraction (XRD) measurements were carried out on Rigaku Ultima IV, in BraggBrentano geometry, using $\mathrm{Cu} K \alpha 1(\lambda=0.15418 \mathrm{~nm})$ radiation operating under $40 \mathrm{kV}$ and $40 \mathrm{~mA}$, and with a scanning range of $2 \theta$ from $10^{\circ}$ to $70^{\circ}$. Scanning electron microscopy (SEM) images were obtained with a JEOL JSM-7500F field emission SEM operated at $2.00 \mathrm{kV}$. X-ray photoelectron spectroscopy (XPS) was conducted on Kratos Analytical Axis Ultra DLD instrument with monochromated Al X-rays at $140 \mathrm{~W}$. The powder UV-Vis diffuse reflectance spectra (DRS) were recorded on Thermo Evolution $300 \mathrm{UV} / \mathrm{Vis}$ spectrophotometer equipped with Praying Mantis diffuse reflectance accessory, and the spectra were collected at a scan rate of $240 \mathrm{~nm} \mathrm{~min}^{-1}$. 
TABLE 2: Synthesis methods used and relevant parameters for the preparation of various $\mathrm{BiVO}_{4}$ samples.

\begin{tabular}{|c|c|c|c|c|}
\hline $\begin{array}{l}\text { Sample (sample } \\
\text { name) }\end{array}$ & Synthesis method & Reactants & $\begin{array}{l}\mathrm{pH} \text { of precursor slurry } \\
\text { (pH control medium) }\end{array}$ & Treatment temperature \& time \\
\hline $\begin{array}{l}\mathrm{BiVO}_{4} \\
\text { (Co-pre-350-24) }\end{array}$ & Coprecipitation [19] & $\begin{array}{l}30 \mathrm{mmol} \mathrm{Bi}\left(\mathrm{NO}_{3}\right)_{3} \cdot 5 \mathrm{H}_{2} \mathrm{O} \\
30 \mathrm{mmol} \mathrm{NH}_{4} \mathrm{VO}_{3} \\
4 \mathrm{M} \mathrm{HNO}_{3} \\
2 \mathrm{M} \mathrm{NH}_{4} \mathrm{OH} \\
9 \% \text { (sodium } \\
\text { carboxymethylcellulose) }_{\mathrm{CMC}^{a}}\end{array}$ & $9\left(2 \mathrm{M} \mathrm{NH}_{4} \mathrm{OH}\right)$ & Calcination at $350^{\circ} \mathrm{C}, 24 \mathrm{~h}$. \\
\hline $\begin{array}{l}\mathrm{BiVO}_{4} \\
(\mathrm{Comb}-500-3)\end{array}$ & Combustion [30] & $\begin{array}{l}2 \mathrm{mmol} \mathrm{Bi}\left(\mathrm{NO}_{3}\right)_{3} \cdot 5 \mathrm{H}_{2} \mathrm{O} \\
2 \mathrm{mmol} \text { citric acid } \\
1 \mathrm{M} \mathrm{HNO}_{3} ; \\
2 \mathrm{mmol} \mathrm{NH}_{4} \mathrm{VO}_{3} \\
5 \mathrm{mmol} \text { citric acid }\end{array}$ & $7.5\left(2 \mathrm{M} \mathrm{NH}_{4} \mathrm{OH}\right)$ & Calcination at $500^{\circ} \mathrm{C}, 3 \mathrm{~h}$. \\
\hline $\begin{array}{l}\mathrm{BiVO}_{4} \\
(\mathrm{Calc}-450-5)\end{array}$ & Calcination [24] & $\begin{array}{l}1 \mathrm{mmol} \mathrm{Bi}\left(\mathrm{NO}_{3}\right)_{3} \cdot 5 \mathrm{H}_{2} \mathrm{O} \\
3 \mathrm{mmol} \mathrm{K}_{2} \mathrm{CO}_{3} \\
5 \mathrm{mmol} \mathrm{V}_{2} \mathrm{O}_{5}\end{array}$ & 1 (no $\mathrm{pH}$ adjustment) & Calcination at $450^{\circ} \mathrm{C}, 5 \mathrm{~h}$. \\
\hline
\end{tabular}

${ }^{\mathrm{a}} 9 \%$ CMC weight percentages related to the total weight of prepared samples.

Samples prepared via coprecipitation synthesis were denoted by the nomenclature $\mathrm{BiVO}_{4}$ (Co-pre-YYY-YY), where YYY and YY refer to the treatment temperature and time, respectively; $\mathrm{BiVO}_{4}(\mathrm{Comb}-\mathrm{YYY}-\mathrm{YY})$ and $\mathrm{BiVO}_{4}$ (Calc-YYY-YY) denote samples prepared via combustion and calcination, respectively.

2.3. Photocatalytic Activity. Photocatalytic performance was quantified by the decomposition of RhB (Sigma-Aldrich) as a model organic pollutant under visible light irradiation. A slurry reactor was placed in a reflective housing to prevent outside light from entering the reactor and inside light from exiting the system. $300 \mathrm{~W}$ ELH tungsten halide bulb (Ushio) was used as a light source with a $410 \mathrm{~nm}$ cut-off filter (Kenko Zeta, $\lambda>410 \mathrm{~nm}$, transmittance $>90 \%$ ) to provide visible light irradiation. The light source was placed at a distance of $15 \mathrm{~cm}$ from the top of the slurry. The corresponding irradiation was measured using a quantum meter (Biospherical QSL-2100; $400 \mathrm{~nm}<\lambda<700 \mathrm{~nm}$ ) and was found to be approximately $4.7 \times 10^{-3}$ Einstein $\mathrm{m}^{-2} \mathrm{~s}^{-1}$. Cooling was provided by an external cooling jacket, and temperature of the reaction was controlled to $22^{\circ} \mathrm{C} \pm 2$. Before illumination, 0.1 grams of photocatalyst dispersed into $150 \mathrm{~mL}$ of $\mathrm{RhB}$ solution $\left(5 \mathrm{mg} \mathrm{L}^{-1}\right)$ was allowed to reach adsorption/desorption equilibration under continuous magnetic stirring at $340 \mathrm{rpm}$ for $30 \mathrm{~min}$ in the dark. Irradiation was then provided for $2 \mathrm{~h}$ for each photocatalytic degradation trial. Samples were withdrawn at 20 min time intervals and separated by centrifugation at $10 \times 10^{3} \mathrm{rpm}$ for $3 \mathrm{~min}$ in accuSpin Micro 17 (Fisher Scientific) microcentrifuge to remove the suspended catalyst, and the supernatant fluid was analyzed by monitoring the peak absorbance $(\lambda=552 \mathrm{~nm}$ for $\mathrm{RhB})$ via a Genesys 10 UV spectrophotometer (Geneq Inc.). A standard curve for $\mathrm{RhB}$ was prepared and the concentration was determined by the measured absorbance and the Beer-Lambert Law. UV/Vis analysis of RhB samples was obtained via Biochrom Ultrospec $60 \mathrm{UV} / \mathrm{Vis}$ spectrophotometer. Quenching tests were performed by the addition of appropriate reactive species scavengers. $2 \mathrm{mg}$ Benzoquinone (BQ) (reagent-grade $\geq 98 \%$, Sigma-Aldrich) was used to trap superoxide radicals $\left(\mathrm{O}_{2}{ }^{-\bullet}\right)$,

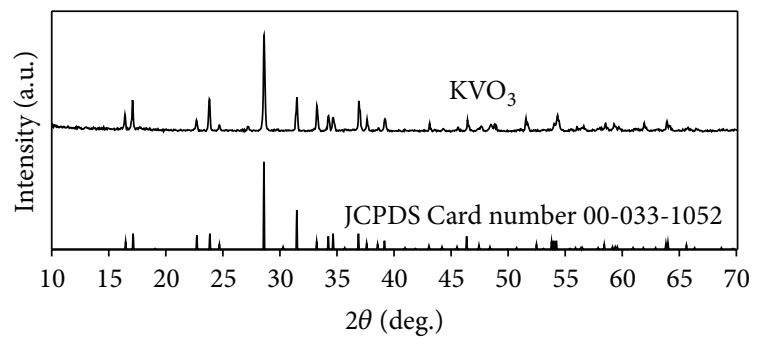

FIGURE 1: XRD pattern of $\mathrm{KVO}_{3}$ powder synthesized from $\mathrm{K}_{2} \mathrm{CO}_{3}$ and $\mathrm{V}_{2} \mathrm{O}_{5}$ via calcination in air at $457^{\circ} \mathrm{C}(730 \mathrm{~K})$ for $5 \mathrm{~h}$; the pattern of orthorhombic $\mathrm{KVO}_{3}$ (JCPDS Card number 00-033-1052) is shown for reference.

$0.15 \mathrm{~g}$ ammonium oxalate (AO) (ACS, Sigma-Aldrich) was used as the holes scavenger, and $3 \mathrm{~mL}$ tert-butyl alcohol (TBA) (ACS, Sigma-Aldrich) was used to trap hydroxyl radicals $\left({ }^{\circ} \mathrm{OH}\right)$, respectively.

\section{Results and Discussion}

3.1. XRD Analysis. The XRD pattern for the $\mathrm{KVO}_{3}$ material obtained by calcination of $\mathrm{K}_{2} \mathrm{CO}_{3}$ and $\mathrm{V}_{2} \mathrm{O}_{5}$ is shown in Figure 1. The diffraction peaks of $\mathrm{KVO}_{3}$ could be well indexed to the orthorhombic phase (JCPDS Card number 00-0331052).

As shown in Figure 1, the XRD pattern for the prepared $\mathrm{KVO}_{3}$ was well indexed to the reference pattern, indicating that pure $\mathrm{KVO}_{3}$ particles with orthorhombic structure resulted from calcination of $\mathrm{K}_{2} \mathrm{CO}_{3}$ and $\mathrm{V}_{2} \mathrm{O}_{5}$ in air at $457^{\circ} \mathrm{C}$ $(730 \mathrm{~K})$ for $5 \mathrm{~h}$. 


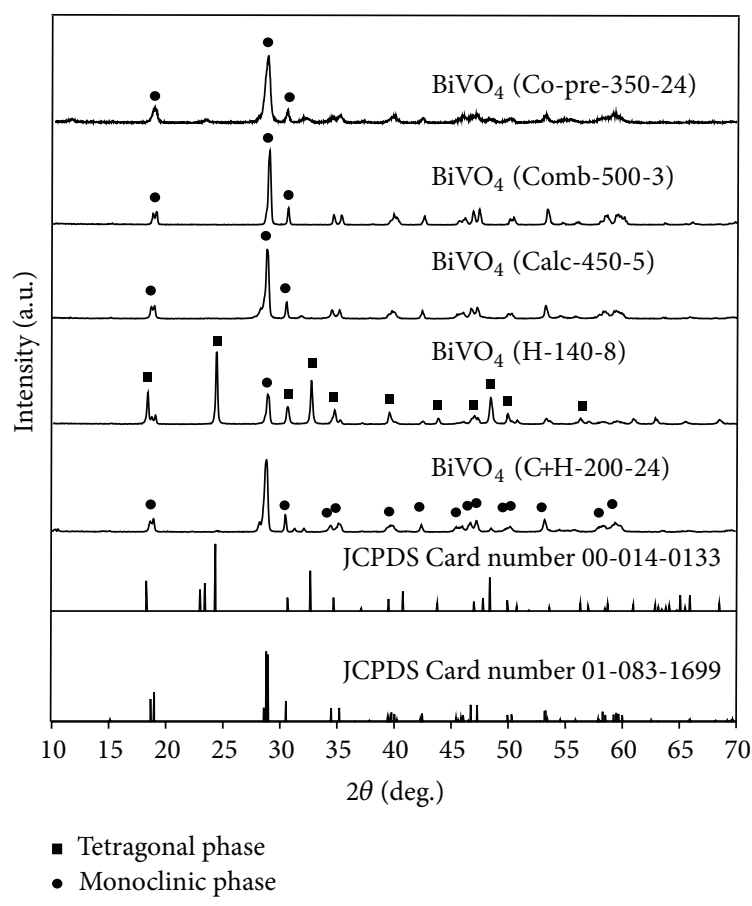

FIGURE 2: XRD patterns of $\mathrm{BiVO}_{4}$ samples synthesized by various methods and conditions (according to Tables 1 and 2). Reference tetragonal and monoclinic $\mathrm{BiVO}_{4}$ are shown for comparison according to JCPDS Card numbers 00-014-0133 and 01-083-1699, respectively.

XRD patterns of $\mathrm{BiVO}_{4}$ obtained via various synthesis methods are shown in Figure 2. For all the prepared photocatalysts, all of the diffraction peaks could be well indexed to the monoclinic scheelite phase of $\mathrm{BiVO}_{4}$ (JCPDS Card number 01-083-1699) with the exception of $\mathrm{BiVO}_{4}(\mathrm{H}-140-8)$ synthesized via hydrothermal method, which was indexed to a tetragonal structure (JCPDS Card number 00-014-0133) but also exhibited monoclinic reflections.

The major reflections observed for the monoclinic $\mathrm{BiVO}_{4}$ structure occurred at $28.8^{\circ}$ and $28.9^{\circ}$, and the major diffraction peak of the tetragonal $\mathrm{BiVO}_{4}$ structure (JCPDS Card number 00-014-0133) occurred at 24.4. As shown in Figure 2, the XRD pattern of $\mathrm{BiVO}_{4}(\mathrm{H}-140-8)$ possessed mixed phases of both tetragonal and monoclinic structures, as evidenced by the characteristic peaks observed at both $24.4^{\circ}$ and $28.8^{\circ}$, respectively. According to the relative intensities of these reflections, the tetragonal structure was thought to be the dominant phase present. All other prepared samples exhibited pure monoclinic structure and were well indexed to the expected reflections according to JCPDS Card number 01-083-1699. $\mathrm{BiVO}_{4}$ sample prepared via coprecipitation (Copre-350-24) was observed to possess lower crystallinity due to the long calcination process used. Sintering was thought to occur at $350^{\circ} \mathrm{C}$ when the sample was annealed for $24 \mathrm{~h}$, which caused the growth of crystalline sizes and consequent decrease of surface area [31]. It was also previously reported in literature that low crystallinity could lead to an increase in the amounts of defects formed relative to the crystalline quantities produced [32]. This low crystallinity and large particle size was found to lead to lower photocatalytic activity $[31,33]$. From the results obtained, the simple calcination process could not be used for the preparation of highly crystalline $\mathrm{BiVO}_{4}$ materials. In contrast, $\mathrm{BiVO}_{4}$ prepared by combustion and calcination (Comb-500-3 and Calc-450-5, resp.) possessed higher crystallinities. The XRD patterns obtained from $\mathrm{BiVO}_{4}$ samples prepared via hydrothermal synthesis (H-140-8 and $\mathrm{C}+\mathrm{H}-200-24$, resp.) indicated that the resulting crystalline structures were dependent on the temperature and time used in the synthesis. However, $\mathrm{BiVO}_{4}(\mathrm{C}+\mathrm{H}-200-24)$ sample prepared via the novel route proposed using $\mathrm{KVO}_{3}$ as the starting material resulted in the formation of a highly crystalline, monoclinic structure which was thought to be advantageous for photocatalysis. The pattern obtained also suggested that higher temperatures and longer reaction times were favorable for the formation of monoclinic $\mathrm{BiVO}_{4}$.

The crystalline size was estimated from the Scherrer formula [34] as follows:

$$
D_{p}=\frac{k \lambda}{\beta_{1 / 2} \cos \theta},
$$

where $D_{p}$ is the crystalline size; $\lambda$ is the wavelength of the $\mathrm{X}$ ray radiation $(\lambda=0.15418 \mathrm{~nm}) ; k$ is the sphericity constant (usually taken as 0.9 ); $\beta_{1 / 2}$ is the peak width at half-maximum height of the sample after subtraction for equipment broadening. In (1), the values of $2 \theta$ were $28.95^{\circ}$ for monoclinic $\mathrm{BiVO}_{4}$ and $24.37^{\circ}$ for tetragonal $\mathrm{BiVO}_{4}$, respectively. The crystalline sizes of $\mathrm{BiVO}_{4}$ prepared via various syntheses are shown in Table 4.

The molar ratio of bismuth to vanadium was thought to influence the formation of monoclinic $\mathrm{BiVO}_{4}$. Therefore, the molar ratio of $\mathrm{Bi}: \mathrm{V}$ was kept at $3: 2$ during hydrothermal synthesis (C+H-200-24) to ensure the formation of monoclinic $\mathrm{BiVO}_{4}$ and provide sufficient vanadium for the stoichiometric conversion from tetragonal to monoclinic $\mathrm{BiVO}_{4}$ [24]. On the basis of our experiments, relevant chemical reactions were formulated as follows:

$$
\begin{gathered}
\mathrm{K}_{2} \mathrm{CO}_{3}+\mathrm{V}_{2} \mathrm{O}_{5} \underset{\text { Calcination }}{\stackrel{457^{\circ} \mathrm{C} \text { for } 5 \mathrm{~h}}{\longrightarrow}} 2 \mathrm{KVO}_{3}+\mathrm{CO}_{2} \uparrow \\
2 \mathrm{KVO}_{3}+3 \mathrm{Bi}\left(\mathrm{NO}_{3}\right)_{3} \cdot 5 \mathrm{H}_{2} \mathrm{O} \underset{\text { Hydrothermal }}{\stackrel{200^{\circ} \mathrm{C} \text { for } 24 \mathrm{~h}}{\longrightarrow}} \mathrm{BiVO}_{4} \\
\mathrm{Bi}\left(\mathrm{NO}_{3}\right)_{3}+\mathrm{H}_{2} \mathrm{O} \leftrightharpoons 2 \mathrm{HNO}_{3}+\mathrm{BiONO}_{3} \\
10 \mathrm{KVO}_{3}+4 \mathrm{H}^{+} \longrightarrow \mathrm{V}_{10} \mathrm{O}_{28}{ }^{6-}+10 \mathrm{~K}^{+}+2 \mathrm{H}_{2} \mathrm{O} \\
10 \mathrm{~K}^{+}+3 \mathrm{~V}_{10} \mathrm{O}_{28}{ }^{6-}+8 \mathrm{H}^{+} \longleftrightarrow 10 \mathrm{KV}_{3} \mathrm{O}_{8}+4 \mathrm{H}_{2} \mathrm{O} \\
3 \mathrm{BiONO}_{3}+\mathrm{V}_{3} \mathrm{O}_{8}{ }^{-}+\mathrm{H}_{2} \mathrm{O} \leftrightharpoons 3 \mathrm{BiVO}_{4}+3 \mathrm{NO}_{3}{ }^{-}+2 \mathrm{H}^{+} \\
\mathrm{CH}_{3} \mathrm{COOH}+\mathrm{NO}_{3}{ }^{-} \leftrightharpoons \mathrm{CH}_{3} \mathrm{COO}^{-}+\mathrm{HNO}_{3}
\end{gathered}
$$

According to Kudo et al. [24] and Liu et al. [28], the formation of $\mathrm{BiVO}_{4}$ was sensitive to temperature and $\mathrm{pH}$ of the aqueous medium. The authors indicated that high temperature $\left(\sim 200^{\circ} \mathrm{C}\right)$ might facilitate the conversion of excess $\mathrm{BiO}^{+}$ 
to the monoclinic structure, by the adsorption on the tetragonal $\mathrm{BiVO}_{4}$ crystals. In addition, under $\mathrm{pH} \sim 1$, the interaction of $\mathrm{BiO}^{+}$cations with $\mathrm{VO}_{3}{ }^{-}$present in $\mathrm{KVO}_{3}$ was thought to be much stronger than with $\mathrm{VO}_{3}{ }^{-}$in $\mathrm{NH}_{4} \mathrm{VO}_{3}$, due to Coulombic attractions.

The increase of the $\mathrm{KVO}_{3}$ solubility in water is greater than that of $\mathrm{NH}_{4} \mathrm{VO}_{3}$ over a temperature range of $293 \mathrm{~K}$ to $323 \mathrm{~K}$ [35], which may have also contributed to providing more $\mathrm{VO}_{3}{ }^{-}$for the generation of $\mathrm{BiVO}_{4}$. Furthermore, $\mathrm{VO}_{3}{ }^{-}$ in $\mathrm{KVO}_{3}$ was reported to be converted to an intermediate product of vanadate ions (i.e., $\mathrm{V}_{10} \mathrm{O}_{28}{ }^{6-}$ ) during the hydrothermal process by increasing temperature, to eventually form a stable $\mathrm{KV}_{3} \mathrm{O}_{8}$ phase [36], as shown in (3a) and (3b). This phase could serve as an inorganic morphology control agent during the synthesis [24].

The $\mathrm{pH}$ value was also thought to influence growth process and the morphology of $\mathrm{BiVO}_{4}$ particles, and the $\mathrm{pH}$ for the precursor slurry of $\mathrm{BiVO}_{4}$ was $\sim 1$ due to the hydrolyses of $\mathrm{Bi}\left(\mathrm{NO}_{3}\right)_{3} \cdot 5 \mathrm{H}_{2} \mathrm{O}$ [24]. The final $\mathrm{pH}$ of $\mathrm{BiVO}_{4}$ precursor slurry was kept at $\sim 1$ by adding 50 vol. $\%$ acetic acid (acidity $\left.\mathrm{p} K_{a}=4.76\right)$. Acetic acid was thought to play the following roles during the synthesis:

(1) Adjusted concentrations between $\mathrm{Bi}(\mathrm{III})$ and $\mathrm{V}(\mathrm{V})$, acting as a morphology controlling agent for $\mathrm{BiVO}_{4}$ [37].

(2) Promoted the conversion from tetragonal $\mathrm{BiVO}_{4}$ to monoclinic $\mathrm{BiVO}_{4}$ crystals resulting in pure monoclinic $\mathrm{BiVO}_{4}$ particles.

(3) Preferentially formed pure monoclinic $\mathrm{BiVO}_{4}$ particles with nanoscaled average crystalline sizes [33].

3.2. SEM Analysis. The microstructure and morphology of synthesized $\mathrm{BiVO}_{4}$ particles were investigated by SEM, and the images obtained are shown in Figures 3 and 4.

From Figures 3(a), 3(b), and 3(c), the as-obtained samples prepared using various methods were observed to be quasispherical with $100 \mathrm{~nm}$ nanoscale length. As shown in the inset of Figure 3(a), clusters of sintered particles were distinctly observed for the sample prepared via coprecipitation instead of individual balls, and this was thought to be due to severe sintering, as expected from the XRD results obtained (Figure $1 \mathrm{BiVO}_{4}$ (Co-pre-350-24)). Comparison of Figures 3(a), 3(b), and 3(c) indicated that the synthesized $\mathrm{BiVO}_{4}$ particles exhibited good morphology evolution which was mainly attributed to shorter calcination times at higher calcination temperatures [24, 38]. From Figure 3(b), the morphology was observed to be composed of nanoscale balls without severe sintering. However, because of the drawbacks associated with calcination synthesis, the surface area of $\mathrm{BiVO}_{4}$ particles formed using the combustion method declined to some extent, which was thought to negatively influence the photocatalytic activity. As seen in Figures 3(d) and 3(e), excellent flake-ball superstructures could be observed for the samples prepared by hydrothermal synthesis. As shown in the inset of Figure 3(d), the morphological evolution of $\mathrm{BiVO}_{4}$ particles from nanoscale flakes and squares to balls with rough surfaces was likely due to the effect of the hydrothermal aqueous system, in which the strong surface-charge driven forces influenced the resulting photocatalyst structures [39, 40]. As the treatment time increased, part of these nanoscale crystals agglomerated to balls. As such, shorter reaction times were thought to provide inadequate surface-charge driven forces for the formation of smooth balls in the hydrothermal processes. Nevertheless, the surface area of $\mathrm{BiVO}_{4}$ particles rapidly increased with treatment time, and multimorphological features of $\mathrm{BiVO}_{4}$ particles were distinctly observed. If various reaction times were used in conjunction with different temperatures, multimorphological features of $\mathrm{BiVO}_{4}$ particles were reported to be more diverse in one system [41]. For instance, flake-ball superstructures with obvious edges were observed in Figure 3(e) (see Figure 3 inset), which agreed well with $\mathrm{BiVO}_{4}$ monoclinic structure seen in the XRD pattern (Figure 2, $\mathrm{BiVO}_{4}(\mathrm{C}+\mathrm{H}-200-24)$ ).

To investigate $\mathrm{BiVO}_{4}(\mathrm{C}+\mathrm{H}-200-24)$, additional SEM imaging was performed, and the results are shown in Figure 4. The multimorphological features observed in the superstructure are highlighted in the insets, where insets 1 , 2 , and 3 indicate flower-like [5], flake-ball and flake [20], cuboid-like, and plate-like structures [21], respectively, which were present in the same system. Iwase and Kudo [37] reported that the edge surfaces of the plate-like and wellcrystallized particles of monoclinic $\mathrm{BiVO}_{4}$ were highly active sites for photocatalytic oxidation reactions. Therefore, monoclinic $\mathrm{BiVO}_{4}$ particles with multimorphological features were thought to be advantageous for photocatalysis due to the increased surface area, resulting in promoting adsorption of dyes onto the photocatalysts and their subsequent photodegradation.

3.3. XPS Analysis. In order to explore the chemical and electronic states of $\mathrm{BiVO}_{4}$, XPS analysis of a representative sample $\left(\mathrm{BiVO}_{4}(\mathrm{C}+\mathrm{H}-200-24)\right)$ was performed, and the results from the full-scan spectrum are shown in Figure 5(a). The corresponding high resolution XPS spectra patterns are presented in Figures 5(b), 5(c), and 5(d), for Bi 4f, V 2p, O 1 s, and $C 1 s$ states, respectively. The spectrum of the $C$ 1s was attributed to the adsorbed carbon present in the samples.

From Figure 5(b), the spectra of Bi species were seen to exhibit two symmetric peaks centered at $158.7 \mathrm{eV}$ and $164 \mathrm{eV}$ (for spin-orbit splitting characteristic of $\mathrm{Bi} 4 \mathrm{f}_{7 / 2}$ and $\mathrm{Bi} 4 \mathrm{f}_{5 / 2}$, resp.) which corresponded to characteristic signals of $\mathrm{Bi}^{3+}$ [42-44]. The observed V 2 $\mathrm{p}_{3 / 2}$ peak (Figure 5(c)) was composed of two components at binding energies of $516.8 \mathrm{eV}$ and $517.2 \mathrm{eV}$, which were assigned to $\mathrm{V}^{4+}$ and $\mathrm{V}^{5+}$ species, respectively, in terms of $\mathrm{V} 2 \mathrm{p}_{3 / 2}$ orbital $[43,45]$. Interestingly, as shown in Figure 5(c), the difference in intensity for those two species was small. Accounting for electroneutrality, $\mathrm{BiVO}_{4}$ (C+H-200-24) had an apparent oxygen deficiency filled with $\mathrm{V}^{4+}$ species [46] incorporated with $\mathrm{V}^{5+}$ species on the surface of $\mathrm{BiVO}_{4}$ in dynamic equilibrium, in which the lost oxygen groups were thought to be consumed to create extra hydroxyl groups on the surface of $\mathrm{BiVO}_{4}$, and these hydroxyl groups generated may have caused the presence of oxygen vacancies [46]. The amount of lost oxygen was determined by the molar ratio of $\mathrm{V}^{4+} / \mathrm{V}^{5+}$ in the whole system $[43,45,47]$. Furthermore, the peak at a binding energy of $524.1 \mathrm{eV}$ was 


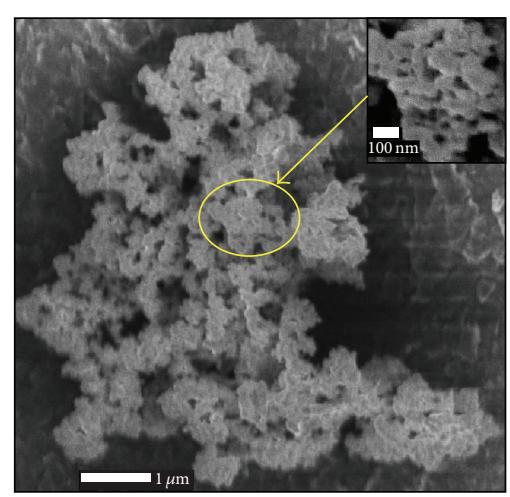

(a)

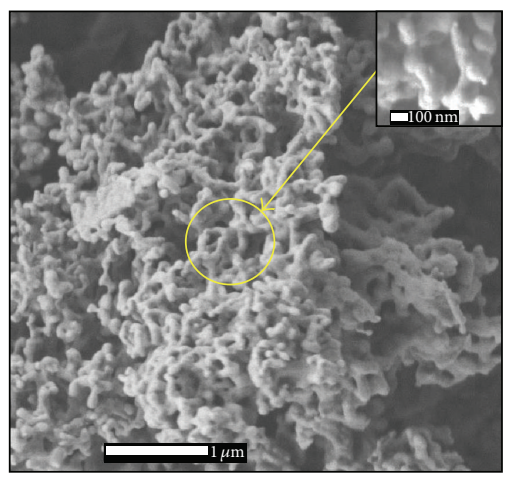

(c)

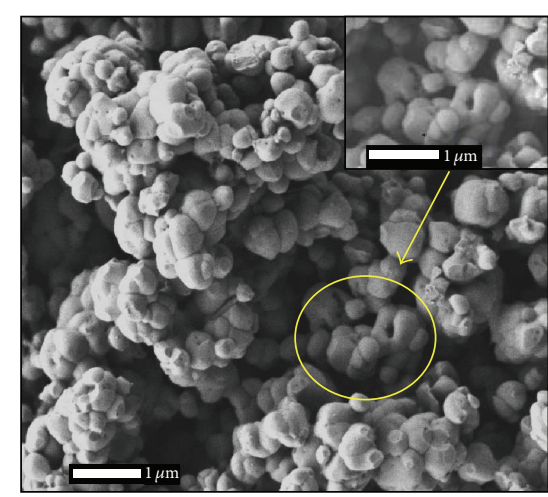

(b)

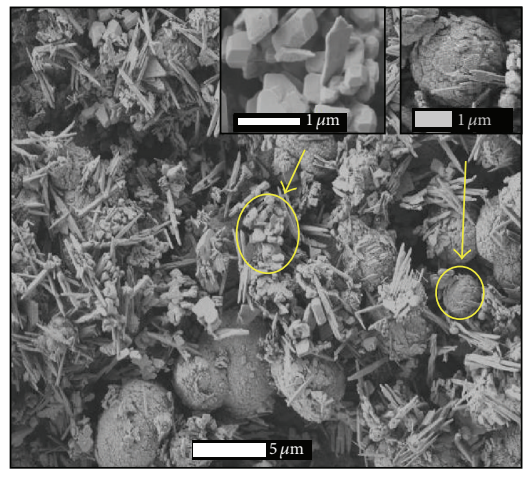

(d)

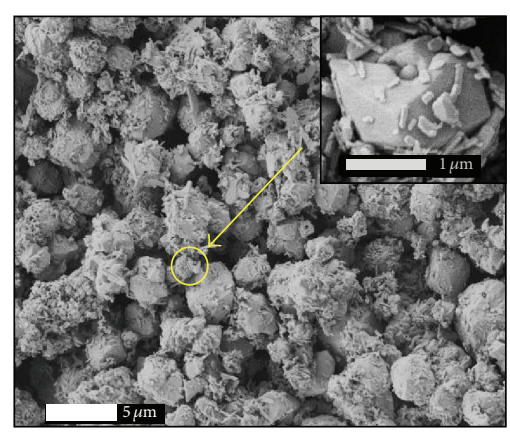

(e)

FIGURE 3: SEM images of $\mathrm{BiVO}_{4}$ samples obtained from various synthesis methods: (a) coprecipitation, (b) combustion, (c) calcination, (d) hydrothermal, (e) calcination and hydrothermal method.

attributed to $\mathrm{V} 2 \mathrm{p}_{1 / 2}$ orbital. As seen in Figure $5(\mathrm{~d})$, the $\mathrm{O}$ 1s spectral peak located at $530 \mathrm{eV}$ was composed of two separate peaks at binding energies of $529.5 \mathrm{eV}$ and $532.1 \mathrm{eV}$. The former peak was characteristic of oxidic species such as $\mathrm{O}^{-}, \mathrm{O}_{2}^{-}$, or $\mathrm{O}^{2-}$ in an effective oxide overlayer [48] and was attributable to oxygen vacancies in $\mathrm{BiVO}_{4-\delta}$ [43]. The latter $\mathrm{O}$ ls peak was assigned to lattice oxygen of $\mathrm{BiVO}_{4}$ crystallites, resulting from interfacial hydroxyl groups (i.e., $\mathrm{OH}$ radicals) or molecularly adsorbed water in the system $[44,48,49]$.

$\mathrm{BiVO}_{4}$ is a direct band gap semiconductor $[6,42]$, which is favourable for retaining low energy direct transitions. In addition to the crystal structure observed, the electronic structure of a semiconductor material affects the photocatalytic activity $[50,51]$. For monoclinic $\mathrm{BiVO}_{4}$, as n-type material [8], V $3 \mathrm{~d}$ orbitals preferentially formed the conduction band $(\mathrm{CB})$, whereas $\mathrm{Bi} 6 \mathrm{~s}$ and $\mathrm{O} 2 \mathrm{p}$ orbitals favoured the composition of a hybridized valence band (VB) [52], where charge transfer occurred from $\mathrm{Bi} 6 \mathrm{~s}$ and $\mathrm{O} 2 \mathrm{p}$ hybrid orbitals to $\mathrm{V} 3 \mathrm{~d}$ orbitals under photoexcitation. The hybridization of $\mathrm{Bi} 6$ s and $\mathrm{O} 2 \mathrm{p}$ levels created a desirably dispersed VB, which could enable the mobility of photoexcited holes [32], resulting in a high activity of photocatalytic oxidation towards organic pollutants [22].

3.4. Optical Properties of $\mathrm{BiVO}_{4}$. As seen in Figure 6, the UV-Vis spectra of all $\mathrm{BiVO}_{4}$ samples exhibited intrinsic absorption in the visible light region attributed to the characteristic features of $\mathrm{BiVO}_{4}$ (both monoclinic and tetragonal phases), which was related to the band-band transition of a semiconductor with a direct band gap $[6,31,52]$. 


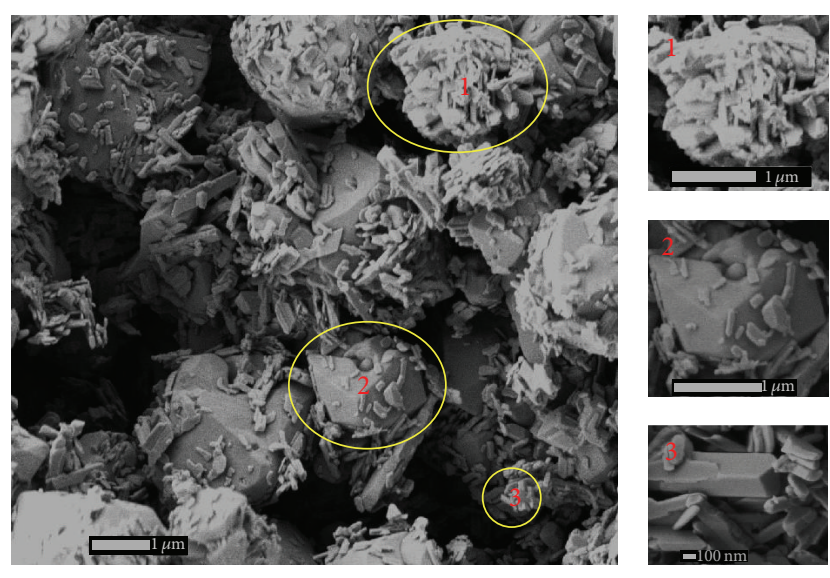

FIgURE 4: SEM image of $\mathrm{BiVO}_{4}$ showing various morphologies.

The band gaps of the prepared samples were estimated from the DRS data, where respective band gap energies $\left(E_{\mathrm{bg}}\right.$, $\mathrm{eV}$ ) were estimated using the following equation:

$$
\lambda=\frac{1240}{E_{\mathrm{bg}}},
$$

where $\lambda$ is the maximum wavelength of absorption by photocatalysts $(\mathrm{nm})$ and $E_{\mathrm{bg}}$ is the estimated band gap of photocatalysts $(\mathrm{eV})$.

The calculated band gap energies were 2.38, 2.30, 2.39, 2.43, and $2.38 \mathrm{eV}$ for $\mathrm{BiVO}_{4}$ (Co-pre-350-24), $\mathrm{BiVO}_{4}$ (Comb500-3), $\mathrm{BiVO}_{4}$ (Calc-450-5), $\mathrm{BiVO}_{4}(\mathrm{H}-140-8)$, and $\mathrm{BiVO}_{4}$ (C+H-200-24) samples, respectively. All of $\mathrm{BiVO}_{4}$ particles prepared via various synthesis methods had strong absorption in the visible light range $(\lambda<510 \mathrm{~nm})$. From the SEM presented in Figure 3(b), $\mathrm{BiVO}_{4}$ (Comb-500-3) sample had the largest agglomerate size due to the severe sintering, and this was thought to have caused the band gap of $2.30 \mathrm{eV}$ observed. In contrast, $\mathrm{BiVO}_{4}\left(\mathrm{Co}-\right.$ pre-350-24), $\mathrm{BiVO}_{4}$ (Calc450-5), $\mathrm{BiVO}_{4}(\mathrm{H}-140-8)$, and $\mathrm{BiVO}_{4}(\mathrm{C}+\mathrm{H}-200-24)$ samples were all present as smaller particles and exhibited band gaps of $2.38,2.39,2.43$, and $2.38 \mathrm{eV}$, respectively. The band gap of a semiconductor has been reported in literature to increase with an absorption shift to shorter wavelengths due to decreased individual particle size $[53,54]$. In accordance with this, a decrease in the light absorption was observed for $\mathrm{BiVO}_{4}(\mathrm{H}-140-8)$ and $\mathrm{BiVO}_{4}(\mathrm{C}+\mathrm{H}-200-24)$ and was thought to be due to the formation of flakes of several hundred nanometers in diameter on the surface of $\mathrm{BiVO}_{4}$ (Figures 3 and 4), which caused the scattering of light [55].

\subsection{Photocatalytic Activity of $\mathrm{BiVO}_{4}$}

3.5.1. Photodegradation of RhB. RhB is a basic red xanthene dye with a high water solubility and a molecular formula of $\mathrm{C}_{28} \mathrm{H}_{31} \mathrm{ClN}_{2} \mathrm{O}_{3}$ [56]. The structure of $\mathrm{RhB}$ is shown in Figure 7 for reference.

$\mathrm{RhB}$ is widely applied as a model target organic pollutant to study photoactivity. The results of visible-light-induced photoactivity in the presence of various prepared $\mathrm{BiVO}_{4}$ samples are shown in Figure 8.
To investigate the self-degradation of $\mathrm{RhB}$, a control test for photolysis in the absence of $\mathrm{BiVO}_{4}$ samples was performed under visible light irradiation. This self-degradation was found to contribute up to $9.6 \%$ in $2 \mathrm{~h}$ of irradiation (Figure 8) and as such may have induced a self-sensitized process. However, compared to the results obtained in the presence of $\mathrm{BiVO}_{4}$ samples, the degree of $\mathrm{RhB}$ self-degradation due to photolysis was thought to have a relatively low contribution to the overall degradation observed in the presence of a photocatalytic process.

In contrast, the $\mathrm{RhB}$ degradation by $\mathrm{BiVO}_{4}(\mathrm{C}+\mathrm{H}-200$ 24) was up to $88 \%$ in $2 \mathrm{~h}$ and represented a higher removal capacity than both photolysis and the other $\mathrm{BiVO}_{4}$ samples prepared, where degradation of $7.2 \%, 6.9 \%, 13 \%$, and $23 \%$ corresponding to $\mathrm{BiVO}_{4}$ (Copre-350-24), $\mathrm{BiVO}_{4}$ (Comb500-3), $\mathrm{BiVO}_{4}$ (Calc-450-5), and $\mathrm{BiVO}_{4}(\mathrm{H}-140-8)$, respectively, was observed, as shown in Figure 8. This indicated that $\mathrm{BiVO}_{4}(\mathrm{C}+\mathrm{H}-200-24)$ was comparatively more active than other $\mathrm{BiVO}_{4}$ samples, and the increase in activity observed was thought to be due to the optimal synthesis method (calcination and hydrothermal) and optimal starting material $\left(\mathrm{KVO}_{3}\right)$ used in the hydrothermal process. These factors acted in concert to create an overall optimized catalyst, which exhibited improved adsorption/desorption kinetics of $\mathrm{RhB}$ on the surface of $\mathrm{BiVO}_{4}$ particles, as well as an improvement in the visible light absorption and photocatalytic degradation.

In addition to the photoactivity observed, the adsorption of $\mathrm{RhB}$ by the prepared $\mathrm{BiVO}_{4}$ samples also influenced the degradation. As a cationic dye in acidic media, the adsorption of $\mathrm{RhB}$ onto a photocatalyst required the presence of anionic catalysts with negative surface charges in order to facilitate photodegradation [57]. As n-type material [8], $\mathrm{BiVO}_{4}$ was a desirable anionic catalyst with respect to the photodegradation of $\mathrm{RhB}$, because it could adsorb the $\mathrm{RhB}$ molecules by Coulombic attractions and also provided extra electrons and created an excess of negative (n-type) electron charge carriers.

3.5.2. Langmuir-Hinshelwood Kinetics. To quantitatively compare the powders synthesized using various conditions, Langmuir-Hinshelwood kinetic analysis was applied to $\mathrm{RhB}$ degradation in the presence of $\mathrm{BiVO}_{4}$ particles. Here the simplification to a pseudo-first-order reaction model is given by the following:

$$
\operatorname{In}\left(\frac{C_{0}}{C}\right)=k_{r} \times K t=k^{\prime} t
$$

where $C_{0}$ and $C$ are the initial $\mathrm{RhB}$ concentration $\left(\mathrm{mol} \mathrm{L}^{-1}\right)$ and concentration at reaction time $t(\mathrm{~min})$, respectively. $k_{r}$ is the reaction rate constant $\left(\mathrm{mg}(\mathrm{L} \cdot \mathrm{min})^{-1}\right), K$ is the adsorption coefficient of the reactant onto catalyst $\left(\mathrm{L} \mathrm{mg}^{-1}\right), k^{\prime}$ is pseudofirst-order rate constant in Langmuir-Hinshelwood expression $\left(\mathrm{min}^{-1}\right)$, and $t$ is the irradiation time $(\mathrm{min})$. The reaction is expressed by the pseudo-first-order equation if adequately dilute initial concentrations are used $\left(C_{0}<10^{-3} \mathrm{~mol} \mathrm{~L}^{-1}\right)$ [58]. In our experiments, $C_{0}$ was adequately small $\left(C_{0}=\right.$ $\left.1.04 \times 10^{-5} \mathrm{~mol} \mathrm{~L}^{-1}\right)$. Hence, $k^{\prime}$ could be used to describe the pseudo-first-order rate constant and was obtained from 


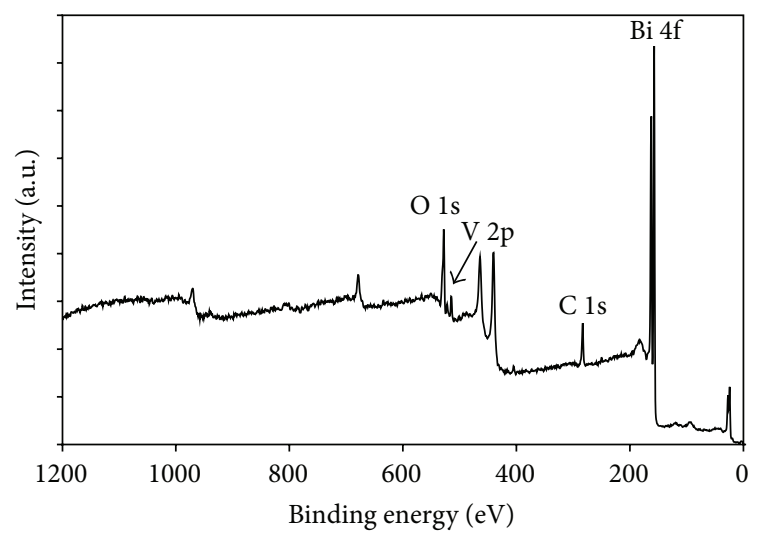

(a)

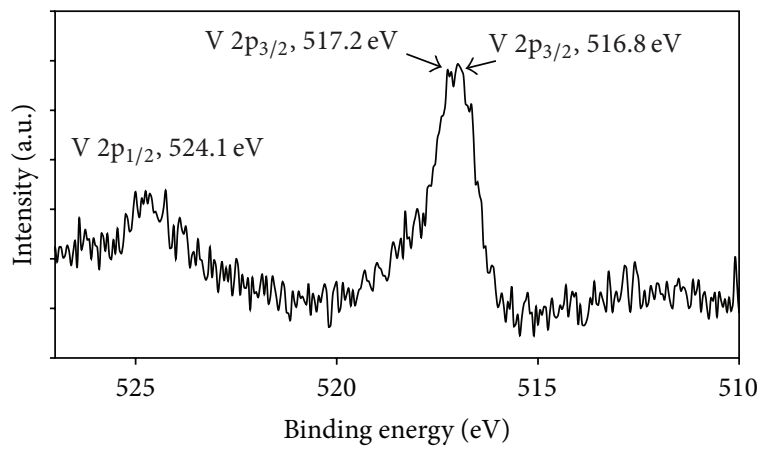

(c)

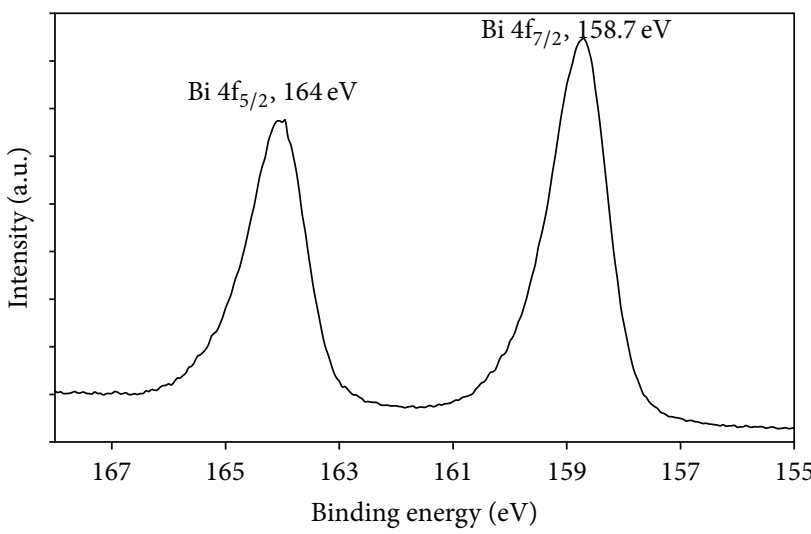

(b)

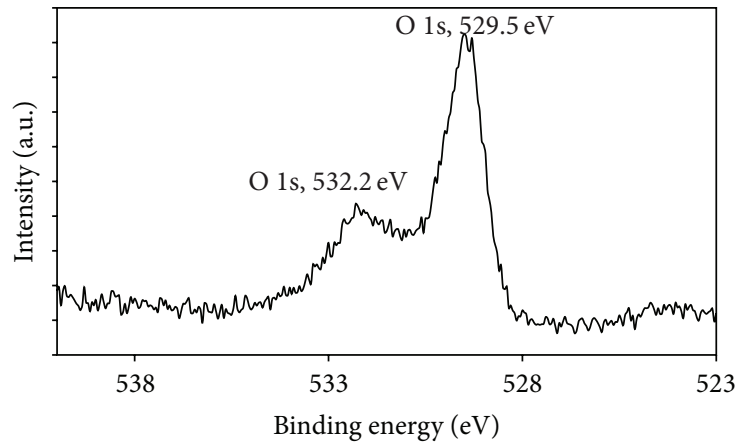

(d)

Figure 5: Full-scan XPS spectrum of $\mathrm{BiVO}_{4}(\mathrm{C}+\mathrm{H}-200-24)$ and high resolution spectra of $\mathrm{Bi} 4 \mathrm{f}, \mathrm{V}$ 2p, and O 1s. (a) Full scan of BiVO Bi 4f, (c) V 2p, and (d) O 1s.

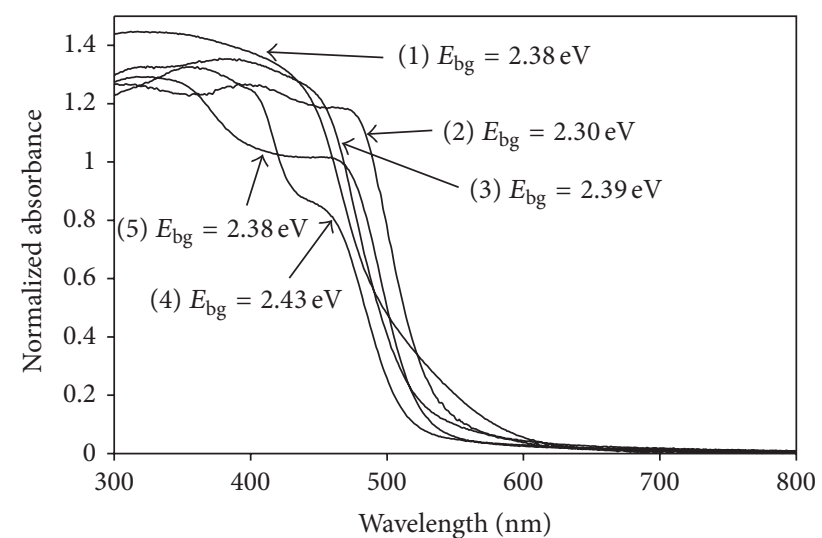

FIGURE 6: UV-Vis diffuse reflectance spectra (DRS) of $\mathrm{BiVO}_{4}$ samples prepared via various synthesis methods, (1) $\mathrm{BiVO}_{4}(\mathrm{Co}-$ pre-350-24), (2) $\mathrm{BiVO}_{4}$ (Comb-500-3), (3) $\mathrm{BiVO}_{4}$ (Calc-450-5), (4) $\mathrm{BiVO}_{4}(\mathrm{H}-140-8)$, and (5) $\mathrm{BiVO}_{4}(\mathrm{C}+\mathrm{H}-200-24)$.

the gradient of the line of $\ln \left(C_{0} / C\right)$ versus time $t$. The pseudofirst-order constant was used as a criterion for the comparison of the photoactivity of the catalysts.

Taking the initial 20 min of degradation into account, the comparison of rate constants obtained is given in Table 3.
TABle 3: Pseudo-first-order rate constants $k^{\prime}$ using LangmuirHinshelwood kinetics for various $\mathrm{BiVO}_{4}$ samples.

\begin{tabular}{lc}
\hline Sample & Degradation rate constants $k^{\prime}\left(\mathrm{min}^{-1}\right)$ \\
\hline $\mathrm{BiVO}_{4}(\mathrm{Co}-$ pre-350-24) & 0.00102 \\
$\mathrm{BiVO}_{4}$ (Comb-500-3) & 0.00127 \\
$\mathrm{BiVO}_{4}$ (Calc-450-5) & 0.00219 \\
$\mathrm{BiVO}_{4}(\mathrm{H}-140-8)$ & 0.00260 \\
$\mathrm{BiVO}_{4}(\mathrm{C}+\mathrm{H}-200-24)$ & 0.0142
\end{tabular}

Note: sample naming follows the previous convention described in Tables 1 and 2.

As seen from Table 3, all samples exhibited photocatalytic activity for the degradation of $\mathrm{RhB}$ to some extent. Of these prepared samples, $\mathrm{BiVO}_{4}(\mathrm{C}+\mathrm{H}-200-24)$ showed the highest degradation rate of $k^{\prime}=0.0142\left(\mathrm{~min}^{-1}\right)$. Therefore, the pseudo-first-order rate constant of $\mathrm{BiVO}_{4}(\mathrm{C}+\mathrm{H}-200-24)$ agreed well with the corresponding result of photocatalytic degradation shown in Figure 8.

3.5.3. Apparent Photonic Efficiency. It has been reported that apparent photonic efficiency can be applied to determining the effectiveness of photon utilization. The initial reaction 
TABLE 4: Properties and photocatalytic performance of $\mathrm{BiVO}_{4}$ samples prepared via various synthesis methods.

\begin{tabular}{lccc}
\hline Sample & Crystalline size $(\mathrm{nm})^{\mathrm{b}}$ & Band gap $(\mathrm{eV})^{\mathrm{c}}$ & Apparent photonic efficiency $\xi$ \\
\hline $\mathrm{BiVO}_{4}($ Co-pre-350-24) & 16 & 2.38 & 0.000410 \\
$\mathrm{BiVO}_{4}$ (Comb-500-3) & 37 & 2.30 & 0.000808 \\
$\mathrm{BiVO}_{4}$ (Calc-450-5) & 30 & 2.39 & 0.00162 \\
$\mathrm{BiVO}_{4}$ (H-140-8) & 51 & 2.43 & 0.00278 \\
$\mathrm{BiVO}_{4}$ (C+H-200-24) & 25 & 2.38 & 0.0131 \\
\hline
\end{tabular}

${ }^{\mathrm{b}}$ By Scherer formula; ${ }^{\mathrm{c}}$ estimated from the diffuse reflectance spectroscopy adsorption edge.

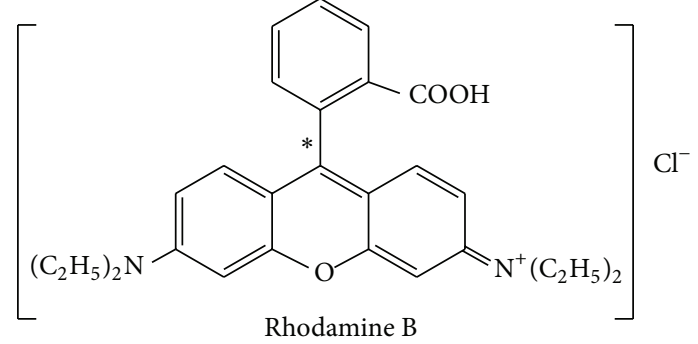

FiguRE 7: Structure of RhB.

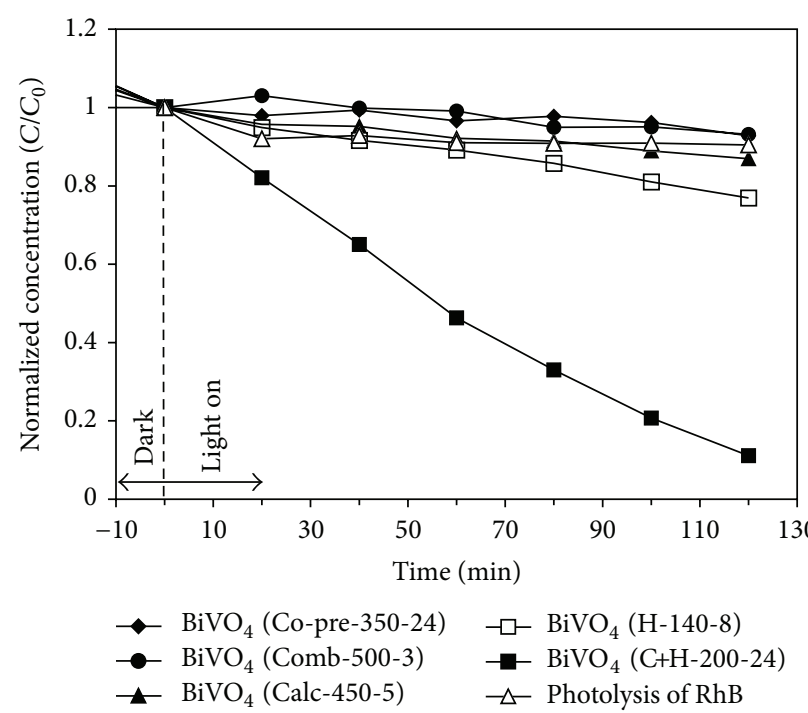

FIgURE 8: Photocatalytic degradation of $\mathrm{RhB}\left(5 \mathrm{mg} \mathrm{L}^{-1}\right)$ in the absence and presence of various $\mathrm{BiVO}_{4}$ samples under visible-light irradiation for $2 \mathrm{~h}$.

within 20 min was considered to be linear, and the photonic efficiency at 20 min was taken as the reference for comparsion of photocatalytic activities among $\mathrm{BiVO}_{4}$ samples. The formula for apparent photonic efficiency is given according to the following [59]:

$$
\xi=\frac{V \Delta C}{J A \Delta t}
$$

where $\xi$ is the apparent photonic efficiency (i.e., the ratio of reaction rate and incident light intensity), $V$ is the solution volume $\left(\mathrm{m}^{3}\right), \Delta C$ is the change in the concentration $\left(\mathrm{mol} \mathrm{m}^{-3}\right), J$ is the flux of photons (Einstein $\left.\mathrm{m}^{-2} \mathrm{~s}^{-1}\right), A$ is the illuminated area $\left(\mathrm{m}^{2}\right)$, and $\Delta t$ is the change in time $(\mathrm{min})$.

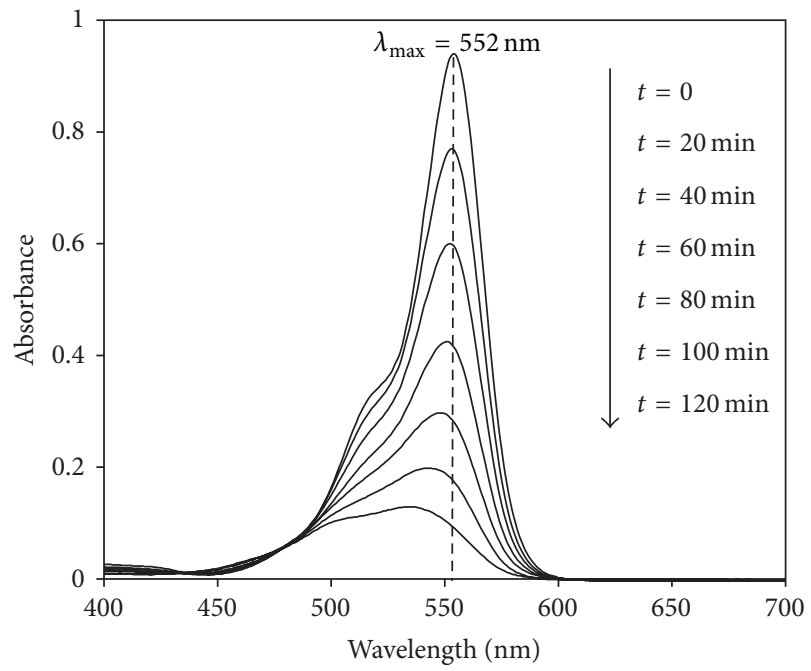

Figure 9: UV-Visible spectra of RhB upon photodegradation by $\mathrm{BiVO}_{4}(\mathrm{C}+\mathrm{H}-200-24)$.

The results of photonic efficiency agreed well with the first-order kinetic constants obtained through LangmuirHinshelwood analysis. $\mathrm{BiVO}_{4}(\mathrm{C}+\mathrm{H}-200-24)$ was found to possess superior photonic effiency to the other samples, with the maximum photonic efficiency of 0.0131 . The calculated values of apparent photonic efficiencies, crystalline size, and band gap of prepared catalysts are shown in Table 4 .

The results indicated that $\mathrm{BiVO}_{4}(\mathrm{C}+\mathrm{H}-200-24)$ via optimized hydrothermal method gave the maximum $k^{\prime}$ value of $0.0142 \mathrm{~min}^{-1}$ corresponding to the highest degree of photocatalytic degradation of $\mathrm{RhB}$, as shown in Figure 8. Table 3 also indicated that the rate constant of $\mathrm{BiVO}_{4}(\mathrm{C}+\mathrm{H}-200$ 24) sample was higher than the other samples prepared via hydrothermal method, indicating that the starting materials affected the overall photocatalytic activity observed.

3.5.4. RhB Degradation. In order to investigate the RhB photocatalytic degradation, the changes of UV-Visible spectrum during the decolorization of $\mathrm{RhB}$ under visible irradiation were investigated, and the results are shown in Figure 9.

As seen in Figure 9, the intensity of characteristic absorption peak at $552 \mathrm{~nm}$ diminished rapidly with time and had gradually hypsochromic shifts of absorption bands from $552 \mathrm{~nm}$ to $535 \mathrm{~nm}$, in agreement with the results reported in literature $[60,61]$. The decline of RhB at its maximum absorption wavelength was attributable to the cleavage of the whole 


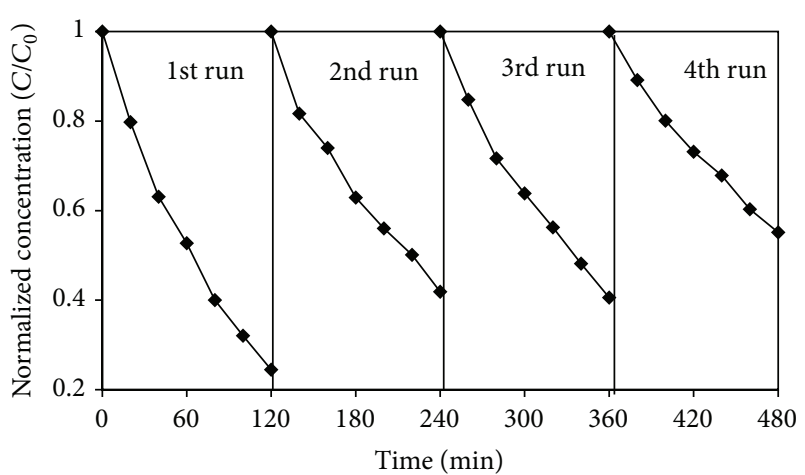

Figure 10: Recycling experiments for the photocatalytic degradation of RhB.

conjugated chromophore structure, while the small shifts from $552 \mathrm{~nm}$ to $535 \mathrm{~nm}$ implied the stepwise $\mathrm{N}$-deethylation of $\mathrm{RhB}$. Generally, those two competitive pathways were thought to occur throughout the whole degradation process. However, from Figure 9, the high initial concentration of $\mathrm{RhB}$ under visible light irradiation may have slowed the production of $\mathrm{N}$-deethylated intermediates. The main reason may be due to the carboxyl group preferentially adsorbing on the surface of $\mathrm{BiVO}_{4}$, rather than that of the diethylamino group at the weak acidic conditions [62], from which the active oxygen species mainly attacked the conjugated chromophore ring structure and resulted in the cleavage of the ring structure of $\mathrm{RhB}$ in the presence of $\mathrm{BiVO}_{4}$. Therefore, the observed absorption shifts were thought to be relatively negligible compared to the decrease in peak absorbance due to the cleavages of the whole conjugated chromophore. Further decomposition of the deethylated intermediates was thought to occur with longer and continuous treatment under visible light irradiation, as reported in literature [57].

3.5.5. Recyclability and Durability of Photocatalytic Activity for $\mathrm{BiVO}_{4}$ Particles. Recyclability of photocatalyst is an important factor for the assessment of practical utilization and scalability of the catalyst. For the recyclability runs, the photocatalyst were separated by centrifugation without washing after each run, and the degraded RhB supernatant was removed, and fresh $\mathrm{RhB}$ solution was added. To assess the recyclability and durability of $\mathrm{BiVO}_{4}(\mathrm{C}+\mathrm{H}-200-24)$ sample for photocatalytic degradation, four runs of recycling experiments were conducted, and the results are shown in Figure 10.

From the results obtained, the concentration of $\mathrm{RhB}$ was seen to obviously decrease in each cycle, implying that $\mathrm{BiVO}_{4}$ $(\mathrm{C}+\mathrm{H}-200-24)$ could exhibit some degree of visible-lightinduced photoactivity in four successive cycling experiments without regeneration. Despite this, some loss of photoactivity after recycling was observed, and the activity in the first run was greater than that observed in the sequential uses at the end of $2 \mathrm{~h}$ visible light irradiation for the second to fourth run, respectively. The $45 \%$ degradation of $\mathrm{RhB}$ observed in the final run indicated that some activity was still maintained by the catalyst, although active sites were thought to be possibly blocked by the intermediates from decomposed $\mathrm{RhB}[63,64]$.

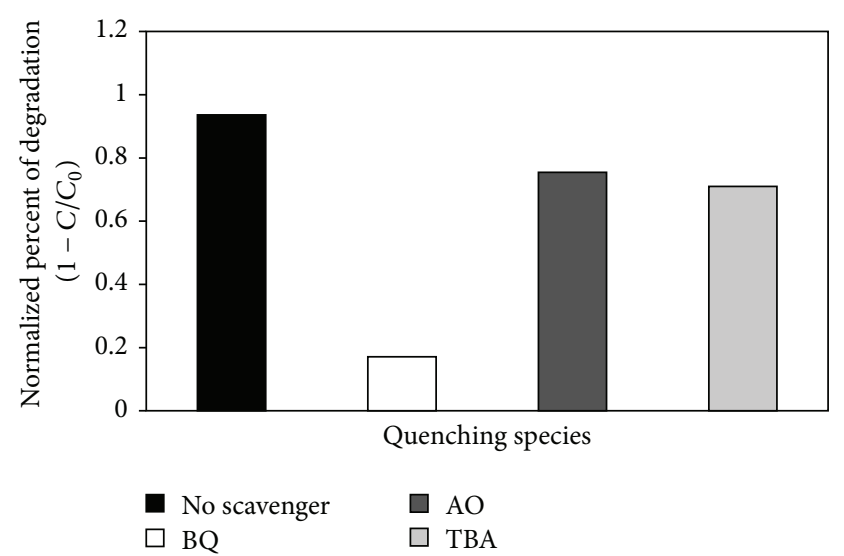

FIGURE 11: Quenching tests for photocatalytic degradation of RhB on $\mathrm{BiVO}_{4}(\mathrm{C}+\mathrm{H}-200-24)$ under different conditions with VLI.

3.5.6. Role of Reactive Species. The photocatalytic degradation of organic pollutants is generally induced by reaction with reactive species such as $\mathrm{h}^{+},{ }^{\bullet} \mathrm{OH}$, and $\mathrm{O}_{2}^{-\bullet}$, which are generated on the surface of photocatalysts upon irradiation [57]. To further investigate the impact of various reactive species on the photocatalytic degradation reactions, the influence of numerous additives was studied on photodegradation of RhB. Reactive species scavengers (including BQ, AO, and TBA) were employed, and their effect on suppressing photocatalytic degradation of $\mathrm{RhB}$ in the presence of $\mathrm{BiVO}_{4}$ was studied. The results are shown in Figure 11.

From Figure 11, it was found that, without scavengers, the photocatalytic degradation of $\mathrm{RhB}$ on $\mathrm{BiVO}_{4}(\mathrm{C}+\mathrm{H}-200$ 24) was $\sim 88 \%$ after 2 hours. Two mg BQ as a scavenger of $\mathrm{O}_{2}{ }^{-\bullet}$ was added in the photocatalytic system $[65,66]$ causing the photodegradation of $\mathrm{RhB}$ on $\mathrm{BiVO}_{4}(\mathrm{C}+\mathrm{H}-200-$ 24) to decrease significantly, reducing the degradation to $17 \%$. This suggested that $\mathrm{O}_{2}^{-\bullet}$ played a significant role in the photocatalytic degradation mechanism of $\mathrm{RhB}$ over $\mathrm{BiVO}_{4}$. $0.15 \mathrm{~g}$ of $\mathrm{AO}$ was used as a hole scavenger $[67,68]$. This addition caused a degradation of $\mathrm{RhB}$ up to $75 \%$, with little change from the unquenched test. Three mL TBA was added into the photodegradation system as ${ }^{\circ} \mathrm{OH}$ scavenger [69] and resulted in $71 \% \mathrm{RhB}$ degradation. From the results of the quenching tests, the degradation of $\mathrm{RhB}$ by $\mathrm{BiVO}_{4}$ under visible light irradiation was thought to be mainly attributed $\mathrm{O}_{2}{ }^{-\bullet}$, where ${ }^{\bullet} \mathrm{OH}$ and holes species played a lesser role in the process.

3.5.7. Mechanism of Photocatalytic Activity. To characterize the photodegradation pathways of the dye pollutant in the absence and presence of $\mathrm{BiVO}_{4}$ under visible light irradiation, considering the results obtained from the photolytic and photocatalytic degradation study, as well as the quenching tests, respectively, the following scheme was proposed:

$$
\begin{aligned}
& \mathrm{RhB}_{\text {ads }}+\text { visible light } \longrightarrow \mathrm{RhB}^{*}{ }_{\text {ads }} \\
& \mathrm{RhB}^{*}{ }_{\text {ads }}+\mathrm{BiVO}_{4} \longrightarrow \mathrm{BiVO}_{4\left(\text { injected e }^{-}\right)}+\mathrm{RhB}^{+} \text {ads }
\end{aligned}
$$




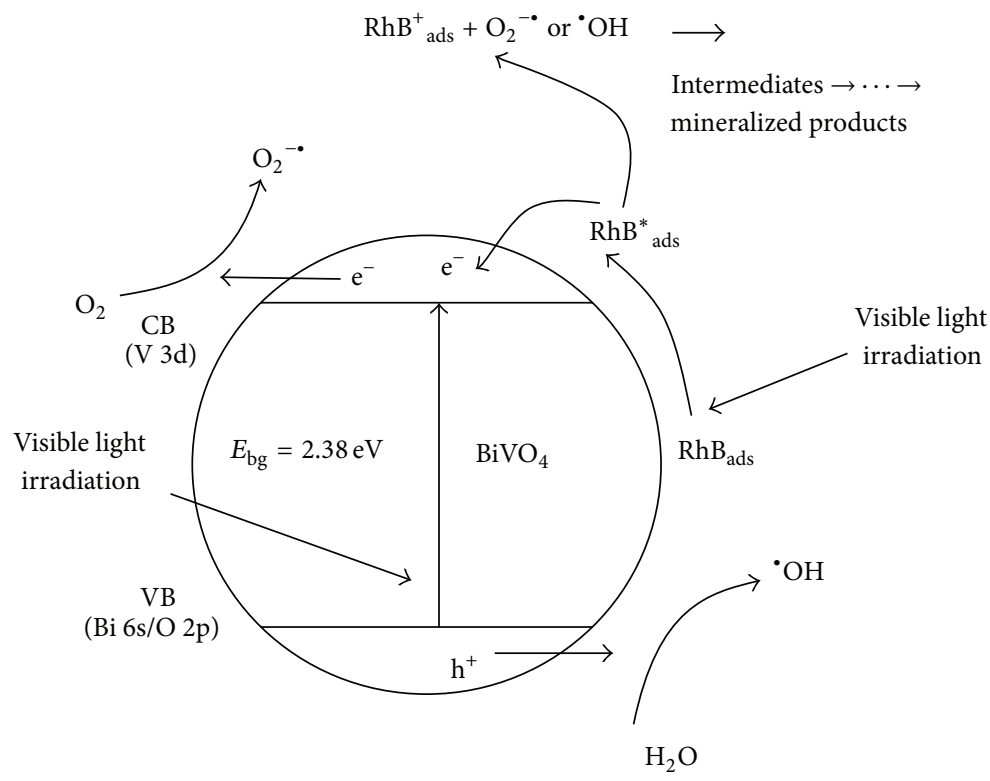

FIgURE 12: Photocatalytic mechanism of $\mathrm{BiVO}_{4}(\mathrm{C}+\mathrm{H}-200-24)$ over $\mathrm{RhB}$ under visible light irradiation.

$$
\begin{aligned}
& \mathrm{BiVO}_{4\left(\text { injected } \mathrm{e}^{-}\right)}+\mathrm{O}_{2 \text { (surface-adsorbed })} \\
& \longrightarrow \mathrm{BiVO}_{4}+\mathrm{O}_{2}^{-\cdot} \\
& \mathrm{BiVO}_{4}+\text { visible light } \longrightarrow \mathrm{h}^{+}+\mathrm{e}^{-} \\
& \mathrm{e}^{-}+\mathrm{O}_{2} \longrightarrow \mathrm{O}_{2}^{-\bullet} \\
& \mathrm{h}^{+}+\mathrm{H}_{2} \mathrm{O} \longrightarrow{ }^{\cdot} \mathrm{OH}
\end{aligned}
$$

$\mathrm{RhB}^{+}{ }_{\text {ads }}+\mathrm{O}_{2}^{-\bullet}$ or ${ }^{\bullet} \mathrm{OH}$ radicals $\rightarrow$ peroxides or hydroxylated $\ldots$ intermediates $\rightarrow$ degraded or mineralized products $[57$, 70].

In accordance with reactions (8)-(11) and Figure 12, the amount of adsorbed RhB and surface-adsorbed molecular oxygen were significant parameters which were dependent on the degree of initial excitation of dye molecules and the yield of molecular oxygen such as $\mathrm{O}_{2}^{-}{ }^{-}$and ${ }^{\bullet} \mathrm{OH}$, which were assumed to be responsible for the dye degradation. From the viewpoint of enhancing photocatalytic degradation of $\mathrm{RhB}$, an optimized photocatalyst with higher adsorption/desorption kinetics of dye was also necessary.

In our research, the optimized $\mathrm{BiVO}_{4}(\mathrm{C}+\mathrm{H}-200-24)$ was able to satisfy these requirements due to its high crystallinity, lower defects content, lower band gap of $2.38 \mathrm{eV}$, and multimorphological features resulting in high visiblelight-induced photocatalytic activity for RhB degradation. In addition, reactions (9a) and (9b) were presumed to occur simultaneously, because $\mathrm{BiVO}_{4}$ particles with a direct band gap around $2.4 \mathrm{eV}$ [42] could be easily excited by visible light. Concurrently, the electron injected from the excited $\mathrm{RhB}^{*}$ ads into the conduction band of $\mathrm{BiVO}_{4}$ facilitated the stepwise degradation of $\mathrm{RhB}^{+}$ads, while the injected electron on the conduction band reduced surface-adsorbed oxidants (e.g., $\mathrm{O}_{2}$ ) (10a). Meanwhile, reactions (10b) and (11) occurred sequentially due to sufficient high-energy $\mathrm{e}^{-}$and $\mathrm{h}^{+}$presented in the system. Furthermore, self-photosensitization of dye occurred during the whole visible-light-induced photodegradation process via oxidizing ${ }^{\circ} \mathrm{OH}$ radicals [70], implying that photosensitization was a possible route due to the photolysis. Despite this, the optimized $\mathrm{BiVO}_{4}(\mathrm{C}+\mathrm{H}-200$ 24) particles exhibited a much higher overall capability for photocatalytic activity presented in Figure 8, where $\mathrm{BiVO}_{4}$ particles acting both as electron donors and as electron carriers played a critical role in transporting electrons to acceptors in order to achieve photocatalytic reactions under visible light irradiation, and these holes and electrons reacted with adsorbed RhB both directly and indirectly, improving the photocatalytic degradation of RhB.

\section{Conclusion}

Fine monoclinic $\mathrm{BiVO}_{4}$ particles were synthesized through a facile hydrothermal method using the synthesized potassium metavanadate $\left(\mathrm{KVO}_{3}\right)$ as precursor. The synthesized $\mathrm{BiVO}_{4}$ (C+H-200-24) particles had a high crystallinity and multimorphological features, and they exhibited good visiblelight-induced photocatalytic activity for the degradation of RhB. A maximum pseudo-first-order degradation rate of $0.0142 \mathrm{~min}^{-1}$ was observed for $\mathrm{BiVO}_{4}(\mathrm{C}+\mathrm{H}-200-24)$. Comparison of the photoactivity observed using samples prepared by various synthesis methods and conditions indicated that adsorption/desorption kinetics, particle size, crystallinity, morphology, and optical properties of photocatalysts all influenced the photoactivity obtained. The hydrothermal synthesis promoted the reaction between $\mathrm{Bi}\left(\mathrm{NO}_{3}\right)_{3} \cdot 5 \mathrm{H}_{2} \mathrm{O}$ and $\mathrm{KVO}_{3}$, and the interaction of $\mathrm{BiO}^{+}$cations with $\mathrm{VO}_{3}{ }^{-}$ from $\mathrm{KVO}_{3}$ was thought to be much stronger than that from $\mathrm{NH}_{4} \mathrm{VO}_{3}$ due to the electrostatic forces present during the synthesis. Additionally, the hydrothermal method facilitated the production of more interfacial ${ }^{\circ} \mathrm{OH}$ radicals on $\mathrm{BiVO}_{4}$ 
particles, promoting reactions between electrons (or holes) and the adsorbed species on $\mathrm{BiVO}_{4}$ particles such as adsorbed $\mathrm{O}_{2}$ and $\mathrm{H}_{2} \mathrm{O}$, in order to prevent photoexcited electrons and holes from recombining, facilitating photocatalytic decomposition.

\section{Conflict of Interests}

The authors declare that there is no conflict of interests regarding the publication of this paper.

\section{Acknowledgments}

This work was funded by the Natural Sciences and Engineering Research Council of Canada (NSERC). The authors would like to thank the Center for Catalysis Research and Innovation and the Department of Earth Sciences at the University of Ottawa, for help with sample characterization, and the Chinese Scholarship Council for the financial support.

\section{References}

[1] K. Shantha and K. B. R. Varma, "Preparation and characterization of nanocrystalline powders of bismuth vanadate," Materials Science and Engineering B: Solid-State Materials for Advanced Technology, vol. 60, no. 1, pp. 66-75, 1999.

[2] L. Ren, L. Jin, J.-B. Wang, F. Yang, M.-Q. Qiu, and Y. Yu, "Template-free synthesis of $\mathrm{BiVO}_{4}$ nanostructures: I. Nanotubes with hexagonal cross sections by oriented attachment and their photocatalytic property for water splitting under visible light," Nanotechnology, vol. 20, no. 11, Article ID 115603, 2009.

[3] S. Tokunaga, H. Kato, and A. Kudo, "Selective preparation of monoclinic and tetragonal $\mathrm{BiVO}_{4}$ with scheelite structure and their photocatalytic properties," Chemistry of Materials, vol. 13, no. 12, pp. 4624-4628, 2001.

[4] A. R. Lim, S. H. Choh, and Min Su Jang, "Prominent ferroelastic domain walls in $\mathrm{BiVO}_{4}$ crystal," Journal of Physics: Condensed Matter, vol. 7, pp. 7309-7323, 1995.

[5] L. Zhou, W. Wang, L. Zhang, H. Xu, and W. Zhu, "Singlecrystalline $\mathrm{BiVO}_{4}$ microtubes with square cross-sections: microstructure, growth mechanism, and photocatalytic property," Journal of Physical Chemistry C, vol. 111, no. 37, pp. 1365913664, 2007.

[6] A. Walsh, Y. Yan, M. N. Huda, M. M. Al-Jassim, and S.-H. Wei, "Band edge electronic structure of $\mathrm{BiVO}_{4}$ : elucidating the role of the Bi s and V d orbitals," Chemistry of Materials, vol. 21, no. 3, pp. 547-551, 2009.

[7] A. Kudo, K. Ueda, H. Kato, and I. Mikami, "Photocatalytic $\mathrm{O}_{2}$ evolution under visible light irradiation on $\mathrm{BiVO}_{4}$ in aqueous $\mathrm{AgNO}_{3}$ solution," Catalysis Letters, vol. 53, no. 3-4, pp. 229-230, 1998.

[8] I. C. Vinke, J. Diepgrond, B. A. Boukamp, K. J. de Vries, and A. J. Burggraaf, "Bulk and electrochemical properties of $\mathrm{BiVO}_{4}$," Solid State Ionics, vol. 57, no. 1-2, pp. 83-89, 1992.

[9] L. Zhou, W. Wang, S. Liu, L. Zhang, H. Xu, and W. Zhu, "A sonochemical route to visible-light-driven high-activity $\mathrm{BiVO}_{4}$ photocatalyst," Journal of Molecular Catalysis A: Chemical, vol. 252, no. 1-2, pp. 120-124, 2006.
[10] N. A. Dhas and K. S. Suslick, "Sonochemical preparation of hollow nanospheres and hollow nanocrystals," Journal of the American Chemical Society, vol. 127, no. 8, pp. 2368-2369, 2005.

[11] C. Li, G. Pang, S. Sun, and S. Feng, "Phase transition of $\mathrm{BiVO}_{4}$ nanoparticles in molten salt and the enhancement of visiblelight photocatalytic activity," Journal of Nanoparticle Research, vol. 12, no. 8, pp. 3069-3075, 2010.

[12] D. Ke, T. Peng, L. Ma, P. Cai, and K. Dai, "Effects of hydrothermal temperature on the microstructures of $\mathrm{BiVO}_{4}$ and its photocatalytic $\mathrm{O}_{2}$ evolution activity under visible light," Inorganic Chemistry, vol. 48, no. 11, pp. 4685-4691, 2009.

[13] T. Yang and D. Xia, "Self-assembly of highly crystalline spherical $\mathrm{BiVO}_{4}$ in aqueous solutions," Journal of Crystal Growth, vol. 311, no. 20, pp. 4505-4509, 2009.

[14] J.-B. Liu, H. Wang, H.-M. Zhang, W.-X. Zhang, and H. Yan, "Preparation of oriented $\mathrm{BiVO}_{4}$ thin film by chemical bath deposition," Chinese Journal of Inorganic Chemistry, vol. 23, no. 7, pp. 1299-1302, 2007.

[15] M. C. Neves and T. Trindade, "Chemical bath deposition of BiVO $_{4}$," Thin Solid Films, vol. 406, no. 1-2, pp. 93-97, 2002.

[16] K. Sayama, A. Nomura, T. Arai et al., "Photoelectrochemical decomposition of water into $\mathrm{H}_{2}$ and $\mathrm{O}_{2}$ on porous $\mathrm{BiVO}_{4}$ thinfilm electrodes under visible light and significant effect of $\mathrm{Ag}$ ion treatment," Journal of Physical Chemistry B, vol. 110, no. 23, pp. 11352-11360, 2006.

[17] A. Galembeck and O. L. Alves, "BiVO thin film preparation by metalorganic decomposition," Thin Solid Films, vol. 365, no. 1, pp. 90-93, 2000.

[18] H.-Q. Jiang, H. Endo, H. Natori, M. Nagai, and K. Kobayashi, "Fabrication and photoactivities of spherical-shaped $\mathrm{BiVO}_{4}$ photocatalysts through solution combustion synthesis method," Journal of the European Ceramic Society, vol. 28, no. 15, pp. 29552962, 2008.

[19] U. M. García-Pérez, S. Sepúlveda-Guzmán, and A. Martínez-De La Cruz, "Nanostructured $\mathrm{BiVO}_{4}$ photocatalysts synthesized via a polymer-assisted coprecipitation method and their photocatalytic properties under visible-light irradiation," Solid State Sciences, vol. 14, no. 3, pp. 293-298, 2012.

[20] Q. Chen, M. Zhou, D. Ma, and D. Jing, "Effect of preparation parameters on photoactivity of $\mathrm{BiVO}_{4}$ by hydrothermal method," Journal of Nanomaterials, vol. 2012, Article ID 621254, 6 pages, 2012.

[21] H. Li, G. Liu, and X. Duan, "Monoclinic $\mathrm{BiVO}_{4}$ with regular morphologies: hydrothermal synthesis, characterization and photocatalytic properties," Materials Chemistry and Physics, vol. 115, no. 1, pp. 9-13, 2009.

[22] G. Li, D. Zhang, and J. C. Yu, “Ordered mesoporous $\mathrm{BiVO}_{4}$ through nanocasting: a superior visible light-driven photocatalyst," Chemistry of Materials, vol. 20, no. 12, pp. 3983-3992, 2008.

[23] F. Rullens, A. Laschewsky, and M. Devillers, "Bulk and thin films of bismuth vanadates prepared from hybrid materials made from an organic polymer and inorganic salts," Chemistry of Materials, vol. 18, no. 3, pp. 771-777, 2006.

[24] A. Kudo, K. Omori, and H. Kato, "A novel aqueous process for preparation of crystal form-controlled and highly crystalline $\mathrm{BiVO}_{4}$ powder from layered vanadates at room temperature and its photocatalytic and photophysical properties," Journal of the American Chemical Society, vol. 121, no. 49, pp. 11459-11467, 1999.

[25] L. Sui, L. Yu, and Y. Zhang, "Surface and catalytic properties of $\mathrm{K} / \mathrm{V}$ catalysts coating on porous $\mathrm{Al}_{2} \mathrm{O}_{3}$ substrate," Journal of 
Dispersion Science and Technology, vol. 28, no. 2, pp. 285-289, 2007.

[26] A. D. Kelmers, "Compounds in the system $\mathrm{KVO}_{3} \cdot \mathrm{V}_{2} \mathrm{O}_{5}$," Journal of Inorganic and Nuclear Chemistry, vol. 23, no. 3-4, pp. 279283, 1961.

[27] M. Trypuć, Z. Torski, and U. Kiełkowska, "Experimental determination of the optimum conditions of $\mathrm{KVO}_{3}$ synthesis based on $\mathrm{KCl}$ and $\mathrm{V}_{2} \mathrm{O}_{5}$ in the presence of steam," Industrial \& Engineering Chemistry Research, vol. 40, no. 4, pp. 1022-1025, 2001.

[28] J. Liu, H. Wang, S. Wang, and H. Yan, "Hydrothermal preparation of $\mathrm{BiVO}_{4}$ powders," Materials Science and Engineering: $B$, vol. 104, no. 1-2, pp. 36-39, 2003.

[29] C.-M. Huang, G.-T. Pan, Y.-C. M. Li, M.-H. Li, and T. C.K. Yang, "Crystalline phases and photocatalytic activities of hydrothermal synthesis $\mathrm{Ag}_{3} \mathrm{VO}_{4}$ and $\mathrm{Ag}_{4} \mathrm{~V}_{2} \mathrm{O}_{7}$ under visible light irradiation," Applied Catalysis A: General, vol. 358 , no. 2, pp. 164-172, 2009.

[30] Z. Zhang, W. Wang, M. Shang, and W. Yin, "Photocatalytic degradation of rhodamine $\mathrm{B}$ and phenol by solution combustion synthesized $\mathrm{BiVO}_{4}$ photocatalyst," Catalysis Communications, vol. 11, no. 11, pp. 982-986, 2010.

[31] J. Yan, G. Wu, N. Guan, L. Li, Z. Li, and X. Cao, "Understanding the effect of surface/bulk defects on the photocatalytic activity of $\mathrm{TiO}_{2}$ : anatase versus rutile," Physical Chemistry Chemical Physics, vol. 15, no. 26, pp. 10978-10988, 2013.

[32] A. Kudo and Y. Miseki, "Heterogeneous photocatalyst materials for water splitting," Chemical Society Reviews, vol. 38, no. 1, pp. 253-278, 2009.

[33] Y. Zhou, K. Vuille, A. Heel, B. Probst, R. Kontic, and G. R. Patzke, "An inorganic hydrothermal route to photocatalytically active bismuth vanadate," Applied Catalysis A: General, vol. 375, no. 1, pp. 140-148, 2010.

[34] J. Yu and A. Kudo, "Effects of structural variation on the photocatalytic performance of hydrothermally synthesized $\mathrm{BiVO}_{4}$," Advanced Functional Materials, vol. 16, no. 16, pp. 2163-2169, 2006.

[35] M. Trypuć and D. I. Stefanowicz, "Solubility in the $\mathrm{KVO}_{3}+$ $\mathrm{NH}_{4} \mathrm{VO}_{3}+\mathrm{H}_{2} \mathrm{O}$ system," Journal of Chemical and Engineering Data, vol. 42, no. 6, pp. 1140-1144, 1997.

[36] H. T. Evans Jr. and S. Block, "The crystal structures of potassium and cesium trivanadates," Inorganic Chemistry, vol. 5, no. 10, pp. 1808-1814, 1966.

[37] A. Iwase and A. Kudo, "Photoelectrochemical water splitting using visible-light-responsive $\mathrm{BiVO}_{4}$ fine particles prepared in an aqueous acetic acid solution," Journal of Materials Chemistry, vol. 20, no. 35, pp. 7536-7542, 2010.

[38] W. Yin, W. Wang, M. Shang, L. Zhou, S. Sun, and L. Wang, " $\mathrm{BiVO}_{4}$ hollow nanospheres: anchoring synthesis, growth mechanism, and their application in photocatalysis," European Journal of Inorganic Chemistry, vol. 2009, pp. 4379-4384, 2009.

[39] J. Joo, B. Y. Chow, M. Prakash, E. S. Boyden, and J. M. Jacobson, "Face-selective electrostatic control of hydrothermal zinc oxide nanowire synthesis," Nature Materials, vol. 10, no. 8, pp. 596601, 2011.

[40] C. Hariharan, "Photocatalytic degradation of organic contaminants in water by $\mathrm{ZnO}$ nanoparticles: revisited," Applied Catalysis A: General, vol. 304, no. 1-2, pp. 55-61, 2006.

[41] W. Yu, J. Wang, Z. Gou, W. Zeng, W. Guo, and L. Lin, "Hydrothermal synthesis of vanadium pentoxide nanostructures and their morphology control," Ceramics International, vol. 39, no. 3, pp. 2639-2643, 2013.
[42] W. E. Morgan, W. J. Stec, and J. R. Van Wazer, "Inner-orbital binding-energy shifts of antimony and bismuth compounds," Inorganic Chemistry, vol. 12, no. 4, pp. 953-955, 1973.

[43] H. Jiang, H. Dai, X. Meng et al., "Hydrothermal fabrication and visible-light-driven photocatalytic properties of bismuth vanadate with multiple morphologies and/or porous structures for methyl orange degradation," Journal of Environmental Sciences, vol. 24, no. 3, pp. 449-457, 2012.

[44] Q. Jia, K. Iwashina, and A. Kudo, "Facile fabrication of an efficient $\mathrm{BiVO}_{4}$ thin film electrode for water splitting under visible light irradiation," Proceedings of the National Academy of Sciences of the United States of America, vol. 109, no. 29, pp. 11564-11569, 2012.

[45] W. Liu, S. Y. Lai, H. Dai, S. Wang, H. Sun, and C. T. Au, "Oxidative dehydrogenation of $\mathrm{n}$-butane over mesoporous $\mathrm{VO}_{x} / \mathrm{SBA}$ 15 catalysts," Catalysis Letters, vol. 113, no. 3-4, pp. 147-154, 2007.

[46] G. Wang, Y. Ling, X. Lu et al., "Computational and photoelectrochemical study of hydrogenated bismuth vanadate," The Journal of Physical Chemistry C, vol. 117, no. 21, pp. 10957-10964, 2013.

[47] W. E. Slink and P. B. DeGroot, "Vanadium-titanium oxide catalysts for oxidation of butene to acetic acid," Journal of Catalysis, vol. 68, no. 2, pp. 423-432, 1981.

[48] G. U. Kulkarni, C. N. R. Rao, and M. W. Roberts, "Nature of the oxygen species at $\mathrm{Ni}(110)$ and $\mathrm{Ni}(100)$ surfaces revealed by exposure to oxygen and oxygen-ammonia mixtures: evidence for the surface reactivity of O-type species," Journal of Physical Chemistry, vol. 99, no. 10, pp. 3310-3316, 1995.

[49] P. M. Blass, X. L. Zhou, and J. M. White, "Coadsorption and reaction of water and potassium on silver(III)," The Journal of Physical Chemistry, vol. 94, pp. 3054-3062, 1990.

[50] D. Wang, J. Tang, Z. Zou, and J. Ye, "Photophysical and photocatalytic properties of a new series of visible-light-driven photocatalysts $\mathrm{M}_{3} \mathrm{~V}_{2} \mathrm{O}_{8}(\mathrm{M}=\mathrm{Mg}, \mathrm{Ni}, \mathrm{Zn})$," Chemistry of Materials, vol. 17, no. 20, pp. 5177-5182, 2005.

[51] H. Fu, C. Pan, W. Yao, and Y. Zhu, "Visible-light-induced degradation of rhodamine $\mathrm{B}$ by nanosized $\mathrm{Bi}_{2} \mathrm{WO}_{6}$," Journal of Physical Chemistry B, vol. 109, no. 47, pp. 22432-22439, 2005.

[52] J. Tang, Z. Zou, and J. Ye, "Efficient photocatalytic decomposition of organic contaminants over $\mathrm{CaBi}_{2} \mathrm{O}_{4}$ under visiblelight irradiation," Angewandte Chemie-International Edition, vol. 43, no. 34, pp. 4463-4466, 2004.

[53] A. Henglein, "Nanoclusters of semiconductors and metals: colloidal nano-particles of semiconductors and metals: electronic structure and processes," Berichte der Bunsengesellschaft für physikalische Chemie, vol. 101, no. 11, pp. 1562-1572, 1997.

[54] D. Beydoun, R. Amal, G. Low, and S. McEvoy, "Role of nanoparticles in photocatalysis," Journal of Nanoparticle Research, vol. 1, no. 4, pp. 439-458, 1999.

[55] J.-G. Yu, H.-G. Yu, B. Cheng, X.-J. Zhao, J. C. Yu, and W.K. Ho, "The effect of calcination temperature on the surface microstructure and photocatalytic activity of $\mathrm{TiO}_{2}$ thin films prepared by liquid phase deposition," The Journal of Physical Chemistry B, vol. 107, no. 50, pp. 13871-13879, 2003.

[56] W.-J. Sun, J. Li, G. Mele, Z.-Q. Zhang, and F.-X. Zhang, "Enhanced photocatalytic degradation of rhodamine B by surface modification of $\mathrm{ZnO}$ with copper (II) porphyrin under both UV-vis and visible light irradiation," Journal of Molecular Catalysis A: Chemical, vol. 366, pp. 84-91, 2013.

[57] J. Zhao, C. Chen, and W. Ma, "Photocatalytic degradation of organic pollutants under visible light irradiation," Topics in Catalysis, vol. 35, no. 3-4, pp. 269-278, 2005. 
[58] J.-M. Herrmann, "Heterogeneous photocatalysis: fundamentals and applications to the removal of various types of aqueous pollutants," Catalysis Today, vol. 53, no. 1, pp. 115-129, 1999.

[59] C. Baumanis and D. W. Bahnemann, "TiO ${ }_{2}$ thin film electrodes: correlation between photocatalytic activity and electrochemical properties," Journal of Physical Chemistry C, vol. 112, no. 48, pp. 19097-19101, 2008.

[60] S. Horikoshi, A. Saitou, H. Hidaka, and N. Serpone, "Environmental remediation by an integrated microwave/UV illumination method. V. Thermal and nonthermal effects of microwave radiation on the photocatalyst and on the photodegradation of Rhodamine-B under UV/Vis radiation," Environmental Science \& Technology, vol. 37, no. 24, pp. 5813-5822, 2003.

[61] Z. He, C. Sun, S. Yang, Y. Ding, H. He, and Z. Wang, "Photocatalytic degradation of rhodamine $\mathrm{B}$ by $\mathrm{Bi}_{2} \mathrm{WO}_{6}$ with electron accepting agent under microwave irradiation: Mechanism and pathway," Journal of Hazardous Materials, vol. 162, no. 2-3, pp. 1477-1486, 2009.

[62] F. Chen, J. Zhao, and H. Hidaka, "Highly selective deethylation of Rhodamine B: adsorption and photooxidation pathways of the dye on the $\mathrm{TiO}_{2} / \mathrm{SiO}_{2}$ composite photocatalyst," International Journal of Photoenergy, vol. 5, no. 4, pp. 209-217, 2003.

[63] J. Liqiang, X. Baifu, Y. Fulong et al., "Deactivation and regeneration of $\mathrm{ZnO}$ and $\mathrm{TiO}_{2}$ nanoparticles in the gas phase photocatalytic oxidation of $\mathrm{n}-\mathrm{C}_{7} \mathrm{H}_{16}$ or $\mathrm{SO}_{2}$," Applied Catalysis A: General, vol. 275, no. 1-2, pp. 49-54, 2004.

[64] M. Long, W. Cai, J. Cai, B. Zhou, X. Chai, and Y. Wu, "Efficient photocatalytic degradation of phenol over $\mathrm{Co}_{3} \mathrm{O}_{4} / \mathrm{BiVO}_{4}$ composite under visible light irradiation," Journal of Physical Chemistry B, vol. 110, no. 41, pp. 20211-20216, 2006.

[65] M. Stylidi, D. I. Kondarides, and X. E. Verykios, "Visible lightinduced photocatalytic degradation of Acid Orange 7 in aqueous $\mathrm{TiO}_{2}$ suspensions," Applied Catalysis B: Environmental, vol. 47, no. 3, pp. 189-201, 2004.

[66] P. Raja, A. Bozzi, H. Mansilla, and J. Kiwi, "Evidence for superoxide-radical anion, singlet oxygen and $\mathrm{OH}$-radical intervention during the degradation of the lignin model compound (3-methoxy-4-hydroxyphenylmethylcarbinol)," Journal of Photochemistry and Photobiology A: Chemistry, vol. 169, no. 3, pp. 271-278, 2005.

[67] H. Lin, H. Ye, S. Chen, and Y. Chen, "One-pot hydrothermal synthesis of $\mathrm{BiPO}_{4} / \mathrm{BiVO}_{4}$ with enhanced visible-light photocatalytic activities for methylene blue degradation," RSC Advances, vol. 4, no. 21, pp. 10968-10974, 2014.

[68] W. Li, D. Li, W. Zhang, Y. Hu, Y. He, and X. Fu, "Microwave synthesis of $\mathrm{Zn}_{x} \mathrm{Cd}_{1-x} \mathrm{~S}$ nanorods and their photocatalytic activity under visible light," Journal of Physical Chemistry $C$, vol. 114, no. 5, pp. 2154-2159, 2010.

[69] J. Wang, X. Yang, J. Chen et al., "Photocatalytic activity of novel $\mathrm{Ag} 4 \mathrm{~V}_{2} \mathrm{O}_{7}$ photocatalyst under visible light irradiation," Journal of the American Ceramic Society, vol. 97, no. 1, pp. 267-274, 2014.

[70] T. Wu, G. Liu, J. Zhao, H. Hidaka, and N. Serpone, "Photoassisted degradation of dye pollutants. V. Self-photosensitized oxidative transformation of Rhodamine B under visible light irradiation in aqueous $\mathrm{TiO}_{2}$ dispersions," Journal of Physical Chemistry B, vol. 102, no. 30, pp. 5845-5851, 1998. 

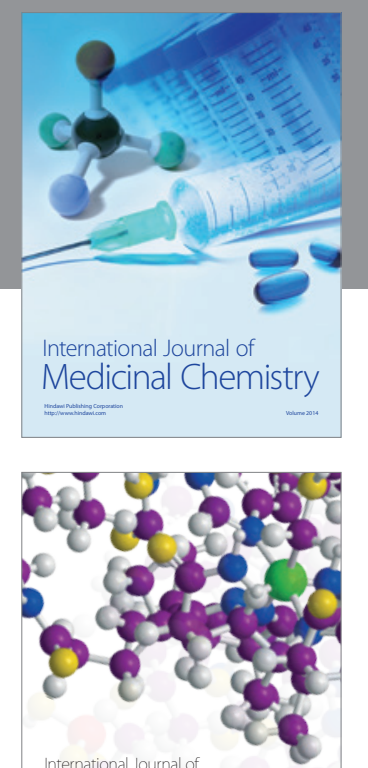

\section{Carbohydrate} Chemistry

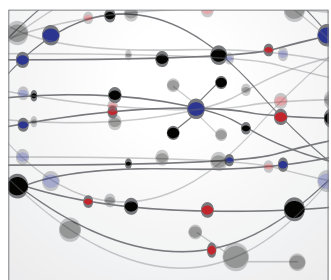

The Scientific World Journal
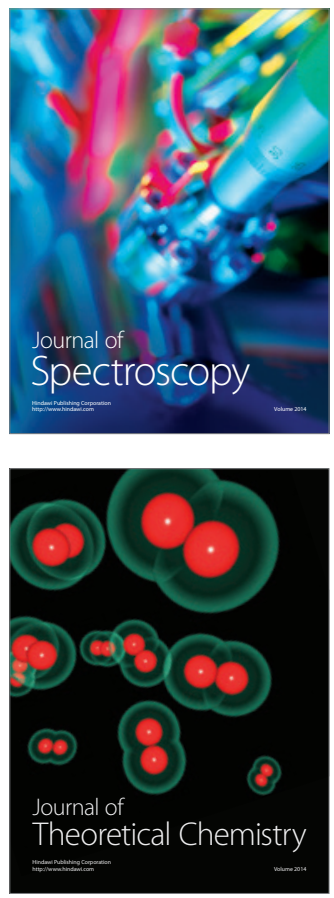
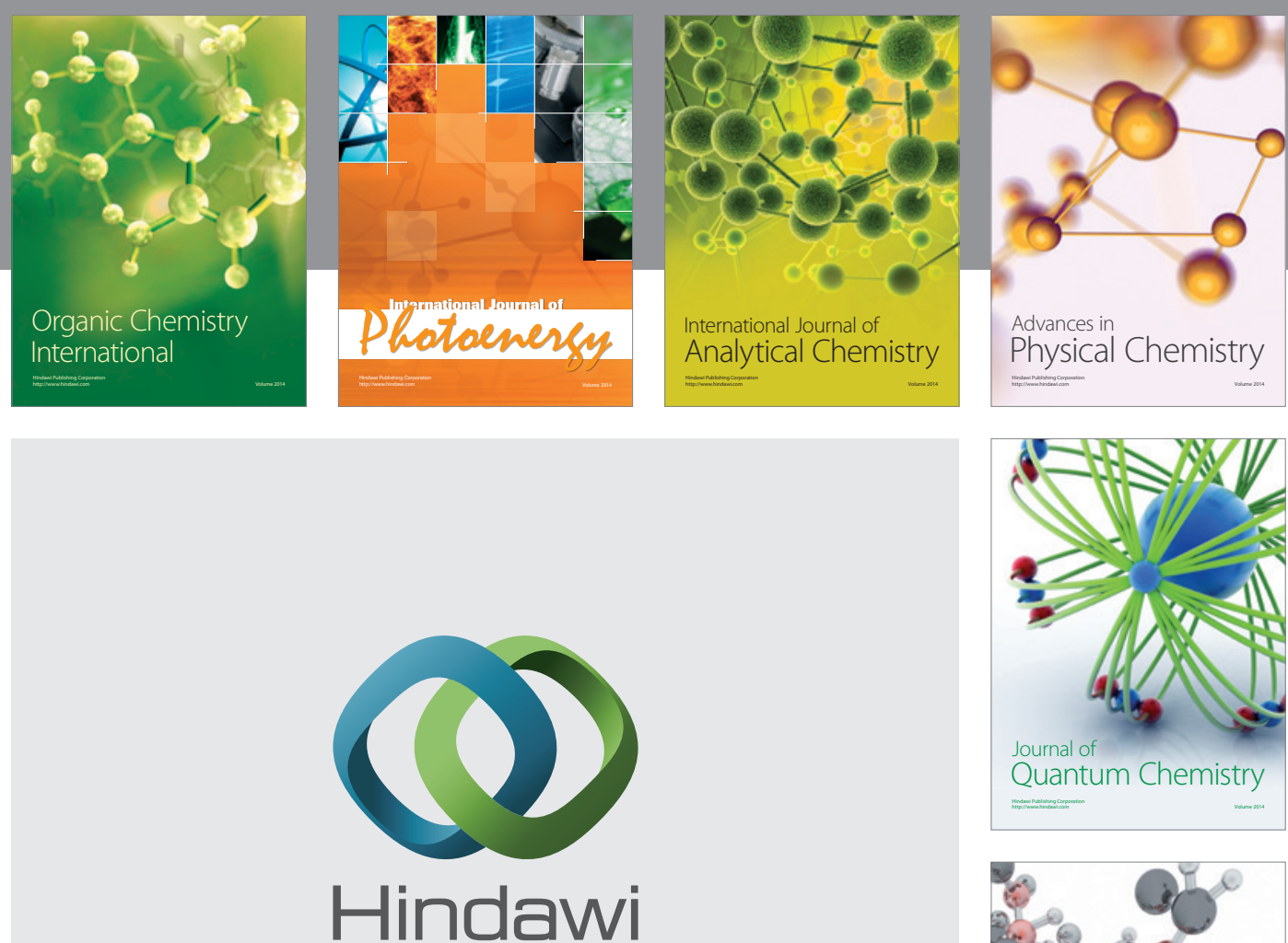

Submit your manuscripts at

http://www.hindawi.com

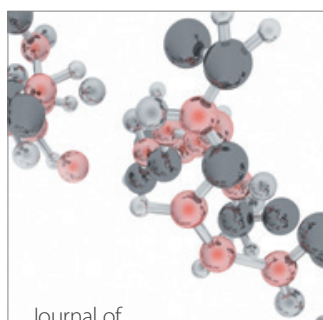

Analytical Methods

in Chemistry

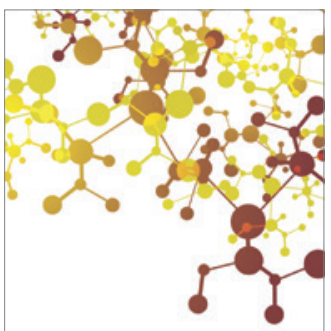

Journal of

Applied Chemistry

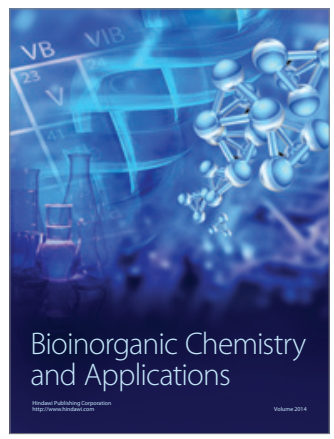

Inorganic Chemistry
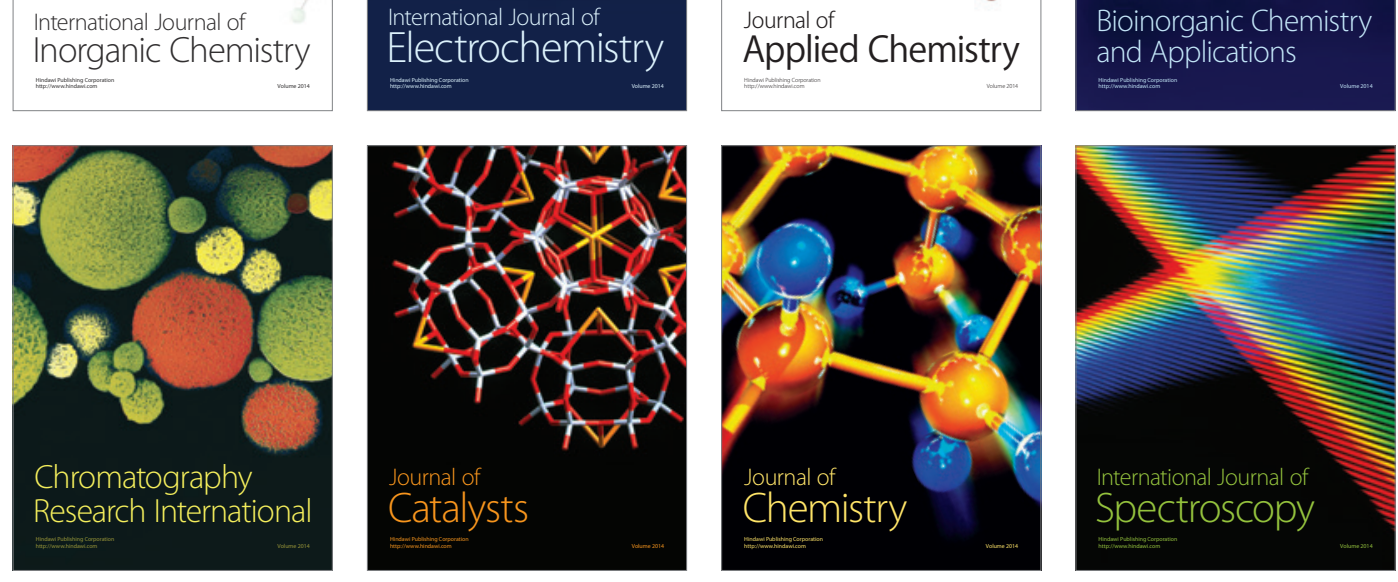